\title{
Sp3/REST/HDAC1/HDAC2 Complex Represses and Sp1/HIF- 1/p300 Complex Activates ncx1 Gene Transcription, in Brain Ischemia and in Ischemic Brain Preconditioning, by Epigenetic Mechanism
}

\author{
Luigi Formisano, ${ }^{1,2 *}$ Natascia Guida, ${ }^{3 *}$ Valeria Valsecchi, ${ }^{1}$ Maria Cantile, ${ }^{1}$ Ornella Cuomo, ${ }^{1}$ Antonio Vinciguerra, ${ }^{1}$ \\ Giusy Laudati, ${ }^{1}$ Giuseppe Pignataro, ${ }^{1}$ Rossana Sirabella, ${ }^{3}$ Gianfranco Di Renzo, ${ }^{1}$ and Lucio Annunziato ${ }^{1,3}$ \\ 'Division of Pharmacology, Department of Neuroscience, Reproductive and Dentistry Sciences, School of Medicine, "Federico II" University of Naples, \\ Naples 80131, Italy, ${ }^{2}$ Division of Pharmacology, Department of Science and Technology, University of Sannio, 82100 Benevento, Italy, and ${ }^{3}$ IRCSS SDN, \\ Naples 80131, Italy
}

The $\mathrm{Na}^{+}-\mathrm{Ca}^{2+}$ exchanger 1 (NCX1) is reduced in stroke by the RE1-silencing transcription factor (REST), whereas it is increased in ischemic brain preconditioning (PC) by hypoxia-inducible factor 1 (HIF-1). Because ncx1 brain promoter (ncx 1-Br) has five putative consensus sequences, named Sp1A-E, for the specificity protein (Sp) family of transcription factors (Sp1-4), we investigated the role of this family in regulating ncx 1 transcription in rat cortical neurons. Here we found that $\mathrm{Sp} 1$ is a transcriptional activator, whereas $\mathrm{Sp} 3$ is a transcriptional repressor of $\mathrm{ncxl}$, and that both bind $\mathrm{ncx} 1-\mathrm{Br}$ in a sequence-specific manner, modulating ncxl transcription through the Sp1 sites C-E. Furthermore, by transient middle cerebral artery occlusion (tMCAO) in rats, the transcriptional repressors Sp3 and REST colocalized with the two histone-deacetylases (HDACs) HDAC1 and HDAC2 on the ncx1-Br, with a consequent hypoacetylation. Contrarily, in PC + tMCAO the transcriptional activators Sp1 and HIF-1 colocalized with histone acetyltransferase p300 on ncx 1-Br with a consequent hyperacetylation. In addition, in neurons silenced with siRNA of NCX1 and subjected to oxygen and glucose deprivation (OGD) (3 h) plus reoxygenation (RX) (24h), the neuroprotection of Class I HDAC inhibitor MS-275 was counteracted, whereas in neurons overexpressing NCX1 and subjected to ischemic preconditioning (PC+OGD/RX), the neurotoxic effect of p300 inhibitor C646 was prevented. Collectively, these results demonstrate that NCX1 expression is regulated by the Sp3/REST/HDAC1/HDAC2 complex in tMCAO and by the Sp1/HIF-1/p300 complex in PC + tMCAO and that epigenetic intervention, by modulating the acetylation of ncxl-Br, may be a strategy for the development of innovative therapeutic intervention in stroke.

Key words: acetylation; brain ischemia; epigenetic; ischemic brain preconditioning; REST URSF; sodium/calcium exchanger

\section{Introduction}

Changes in the $\mathrm{Na}^{+}-\mathrm{Ca}^{2+}$ exchanger 1 ( ncxl) gene expression, a ubiquitous plasma membrane protein regulating cellular calcium and sodium homeostasis in the brain, is important for the pro-

Received May 28, 2014; revised March 18, 2015; accepted March 22, 2015.

Author contributions: L.F., N.G., V.V., and L.A. designed research; L.F., N.G., V.V., M.C., O.C., A.V., G.L., G.P., and R.S. performed research; V.V. contributed unpublished reagents/analytic tools; L.F. and N.G. analyzed data; L.F., N.G., G.D.R., and L.A. wrote the paper.

This work was supported by Ministero dell'Istruzione, dell'Università e della Ricerca Grant PON PON01_01602 and PON03PE_00146_1 all to L.A. We thank Dr Paola Merolla for editorial revision and all the members of the L.A. laboratory for their constructive comments on the data and the manuscript; Prof. Antonella Scorziello and Dr Maria Josè Sisalli for teaching us the rat neuronal culture and for many stimulating discussions; and Prof. Nicola Zambrano for helping us to perform and analyze EMSA experiments.

The authors declare no competing financial interests.

*L.F. and N.G. contributed equally to this work.

Correspondence should be addressed to Dr. Lucio Annunziato, Division of Pharmacology, Department of Neuroscience, Reproductive and Dentistry Sciences, School of Medicine, "Federico II" University of Naples, Via Sergio Pansini 5, Naples 80131, Italy. E-mail: lannunzi@unina.it.

V. Valsecchi's present address: Department of Neuroscience, University of Torino, Torino, Italy, and Neuroscience Institute of Cavalieri Ottolenghi Foundation, University of Torino, Torino, Italy.

DOI:10.1523/JNEUROSCI.2174-14.2015

Copyright $\odot 2015$ the authors $\quad 0270-6474 / 15 / 357332-17 \$ 15.00 / 0$ gression of stroke (Annunziato et al., 2004; Pignataro et al., 2004) and for the reduction of the cerebral infarct damage elicited by ischemic preconditioning (Valsecchi et al., 2011; Pignataro et al., 2012). Indeed, studies have shown that $n c x 1$ ablation markedly increases infarct volume after stroke (Pignataro et al., 2004; Boscia et al., 2006) and partially reverts preconditioning-induced neuroprotection (Pignataro et al., 2012). We previously demonstrated that in an in vivo model of stroke, obtained by transient middle cerebral artery occlusion (tMCAO), NCX1 reduction is due to RE1-Silencing Transcription factor (REST) (Formisano et al., 2013), which regulates global gene expression after stroke (Noh et al., 2012; Schweizer et al., 2013; Kaneko et al., 2014). Instead, NCX1 increase in ischemic preconditioning plus ischemia $(\mathrm{PC}+\mathrm{tMCAO})$ is determined by hypoxia-inducible factor 1 (HIF-1) (Valsecchi et al., 2011). Interestingly, the $n c x 1$ brain promoter (ncxl-Br) sequence contains several consensus binding sites for Specific protein 1 ( $\mathrm{Sp} 1)$. Sp proteins comprise four isoforms, Sp1-Sp4 (Suske, 1999), which recognize the same Sp1 sequence with similar affinities (Hwang et al., 2001). The only exception is Sp2, which binds to a GT-rich element instead (Philipsen and Suske, 1999). Sp1, Sp3, and Sp4 can act as either 
activators (Ammanamanchi et al., 2003; Ishimaru et al., 2007; Ravache et al., 2010) or repressors (Ammanamanchi and Brattain, 2001; Ramos et al., 2009; Law et al., 2011) of gene expression. Therefore, both the presence of several binding sites for Sp1 on the ncxl-Br region and that Sp1 is involved in NGF-induced regulation of NCX1 (Sirabella et al., 2012) prompted us to investigate the relationship between the members of the Sp family and its role in modulating NCX1 expression during tMCAO and $\mathrm{PC}+\mathrm{tMCAO}$. Furthermore, because REST reduces NCX1 expression during tMCAO (Formisano et al., 2013) and HIF-1 increases NCX1 expression during $\mathrm{PC}+\mathrm{tMCAO}$, we also investigated the possible interaction between REST and Sp3 and between HIF-1 and Sp1 after tMCAO and PC+tMCAO, respectively. In addition, because both REST and Sp3 modulate their target genes via the histone deacetylase (HDAC) family (Won et al., 2002; Rodenas-Ruano et al., 2012), we investigated whether the interaction between REST and Sp3 forms a protein complex which, in turn, recruits HDAC1 and HDAC2, thus repressing $n c x 1$ expression after tMCAO. Moreover, considering that histone acetyl transferase (HAT) is involved in gene expression induced by HIF-1 and Sp1 (Billon et al., 1999; Ke and Costa, 2006), we investigated whether the interaction between HIF-1 and Sp1 forms a protein complex that recruits the HAT p300, and activates $n c x 1$ expression after PC+tMCAO. Finally, we assessed the effect of the Class I HDAC inhibitor MS-275 (Lanzillotta et al., 2013; Formisano et al., 2015b) and of the HAT p300 inhibitor C646 (Min et al., 2010) on cell survival and its correlation with NCX1 expression in neurons subjected to either oxygen and glucose deprivation followed by reoxygenation (OGD/RX) or PC plus OGD/RX.

\section{Materials and Methods}

\section{Materials}

All restriction enzymes and DNA-modifying enzymes were purchased from New England Biolabs or Promega. Luciferase reporter kits and luciferase vectors were from Promega. Synthetic oligonucleotides were from Primm. siRNAs against rat REST and HIF-1 were performed as already published (Formisano et al., 2013), whereas siRNAs for Sp1 (siSp1) (SI02039044), Sp3 (siSp3) (SI05434387), Sp4 (siSp4) (SI02039114), p300 (sip300) (SI02989693), and negative control siCONTROL (siCTL) (1027280) were from QIAGEN. To knock down rat $\mathrm{HDAC1}$ and HDAC2,MISSION siRNAs from Sigma were used. The sequences of siRNAs were as follows: for HDAC1 forward, $5^{\prime}$ CUUUGAAUACUUUGGACCA(dT) (dT)-3' and reverse, $5^{\prime}$-UGGU CCAAAGUAUUCAAAG(dT) (dT)-3'; for HDAC2 forward, 5'-GAU AUCGGGAAUUAUUAUU(dT) (dT)-3' and reverse, 5' -AAUAAUA AUUCCCGAUAUC(dT) (dT)-3'. Two sets of siRNAs were tested for Sp1, Sp3, Sp4, p300, HDAC1, and HDAC2. The set that was more effective was chosen for the experiments (data not shown). The construct used to silence NCX1 (siNCX1) and the mismatch sequence cloned in the same vector (MS siNCX1) were used as previously described (Formisano et al., 2008; Sirabella et al., 2009). The constructs pN3 and pN3-Sp1, pN3-Sp3, and pN3-Sp4, carrying Sp1, Sp3, and Sp4 cDNAs, were kindly provided by Prof. G. Suske (Marburg, Germany). The constructs pKCRH-NCX1 overexpressing canine NCX1 and the empty vector ( $\mathrm{pKCRH}$ ) were kindly provided by Prof. Iwamoto (Fukuoka, Japan) (Iwamoto et al., 2004). The HDAC inhibitor MS-275 (EPS002) and the HAT-inhibitor C646 (SML002) were obtained from Sigma. Both were dissolved in DMSO and diluted with cell culture medium. The final concentration of DMSO was $<0.2 \%$. All common reagents were of the highest quality and were purchased from Sigma.

\section{Cell cultures}

Human neuroblastoma SH-SY5Y cells were prepared as previously described (Guida et al., 2014). Primary cortical neurons were prepared from 17-day-old Wistar rat embryos (Charles River) and used after $7 \mathrm{~d}$.
Cytosine arabinoside $(2.5 \mu \mathrm{M})$ was added on the second day to reduce glial contamination. The experiments on primary cortical neurons were performed according to the experimental protocols approved by the Ethics Committee of "Federico II" University of Naples. Briefly; dissection and dissociation were performed in $\mathrm{Ca}^{2+} / \mathrm{Mg}^{2+}$-free PBS containing glucose $(30 \mathrm{~mm})$. Tissues were incubated with papain for $10 \mathrm{~min}$ at $37^{\circ} \mathrm{C}$ and dissociated by trituration in Earl's Balanced Salt Solution containing DNase $(0.16 \mathrm{U} / \mathrm{ml}), \mathrm{BSA}(10 \mathrm{mg} / \mathrm{ml})$, and ovomucoid $(10 \mathrm{mg} / \mathrm{ml})$. Neurons, plated in plastic Petri dishes (Falcon Becton-Dickinson) precoated with poly-D-lysine $(20 \mu \mathrm{g} / \mathrm{ml})$, were grown in MEM/F12 containing glucose, deactivated FBS (5\%), horse serum (5\%), glutamine (2 mM), penicillin $(50 \mathrm{U} / \mathrm{ml})$, and streptomycin $(50 \mu \mathrm{g} / \mathrm{ml})$ (Invitrogen). For LDH assay, cells were plated in 24 well plates at a density of $1 \times 10^{6}$ cells/well; for luciferase assay, they were plated in 12 well plates at a density of $2 \times$ $10^{6}$ cells/well; for qRT-PCR, they were plated in $60 \mathrm{~mm}$ well plates at a density of $5 \times 10^{6}$ cells/well; for Western blot and chromatin immunoprecipitation (ChIP) analyses, they were plated in $100 \mathrm{~mm}$ well plates at a density of $15 \times 10^{6}$ cells/well.

\section{Transfection with expression plasmids or small interfering RNA (siRNA) and luciferase reporter assay, in cortical neurons} Cortical neurons were transfected with $50 \mathrm{~nm}$ of rat siCTL, siSp1, siSp3, or siSp4 (for catalog numbers, see Materials). To overexpress pN3, Sp1, Sp3, and Sp4, pKCRH and pKCRH-NCX1, neurons were transfected with the above mentioned constructs in the following amounts: $0.5 \mu \mathrm{g}$ for 24 well plates, $1.3 \mu \mathrm{g}$ for 12 well plates, $7 \mu \mathrm{g}$ for $60 \mathrm{~mm}$ plates, and 15 $\mu \mathrm{g}$ for $100 \mathrm{~mm}$ plates. Each transfection was performed at 7 DIV in OptiMEM together with Lipofectamine LTX (15338-100, Invitrogen), as suggested by the producer. After a $2 \mathrm{~h}$ transfection, the medium was replaced with a fresh one. To silence NCX1 with siNCX1 and MS-NCX1 (siCTL) neurons were transfected as previously reported (Sirabella et al., 2009). In particular, cells were transfected with $0.5 \mu \mathrm{g}$ for 24 well plates (for LDH assay) and $15 \mu \mathrm{g}$ for $100 \mathrm{~mm}$ plates (for Western blot analysis) of the above mentioned constructs. For luciferase assay experiments, cortical neurons were transfected in 12 well plates. Cells were cotransfected with $2 \mu \mathrm{g}$ of total DNA vectors; the reporters (560 ng each) were as follows: (1) the pGL3-Basic (pGL3) construct; (2) the pGL3-ncx1 (-340/151) contained a $350 \mathrm{bp}$ fragment, named (short ncxl promoter) (Valsecchi et al., 2011); (3) the pGL3-ncx1/Sp1Bmut (GGCGGCGGGC); (4) the pGL3-ncx1/Sp1Cmut (CGGGCGGGG); (5) the pGL3-ncx1/Sp1Dmut (GGGAGGGG); (6) the pGL3-ncx1/Sp1Emut (GGCCCCGGC); and (7) the pGL3-ncx1/Sp1CDEmut. This last reporter contained the simultaneous mutations of the Sp1 binding sites C, D, and E. Each italicized base represents the mutated sequences in pGL3. Each ncx1/Sp1 site was mutated by GG > TT substitution. Mutagenesis of the Sp1 sites in the promoter was performed using the QuikChangeSite-Directed Mutagenesis Kit from Stratagene. To overexpress Sp1, Sp3, and Sp4, we used expression vectors and the empty vector $\mathrm{pN} 3$ (1.3 $\mu \mathrm{g}$ each). For RNA interference, a concentration of $50 \mathrm{~nm}$ of specific siCTL, siSp 1, siSp3, or siSp 4 was used. Each transfection mix also contained $140 \mathrm{ng}$ of the pRL-TK control vector expressing the Renilla luciferase gene. After $2 \mathrm{~h}$ of incubation, the medium was replaced with a fresh one and analyzed after $24 \mathrm{~h}$ with the Dual-Luciferase Reporter Assay System kit (E1910) (Promega), as already reported (Formisano et al., 2013). SHSY-5Y cells (70\% of confluence) were plated in $100 \mathrm{~mm}$ dishes and transiently cotransfected with 9 $\mu \mathrm{g}$ of constructs carrying cDNA for $\mathrm{Sp} 1$ and $\mathrm{Sp} 3$ or with $\mathrm{pN} 3$ and with 6 $\mu \mathrm{g}$ of (1) pGL3-ncx1, (2) pGL3-ncx1 Sp1/C mut, (3) pGL3-ncx1 Sp1/D mut, (4) pGL3-ncx1 Sp1/E mut, and (5) pGL3-ncx1 Sp1/CDE mut using lipofectamine in Opti-MEM, for $6 \mathrm{~h}$. After this time, the medium was changed to normal DMEM. Cells were harvested $48 \mathrm{~h}$ after transfection and lysed for Western blot analysis. Transfection efficiency was $\cong 60 \%$ for SH-SY5Y cells and $\cong 40 \%$ for cortical neurons (data not shown).

\section{Combined OGD and RX}

OGD was performed in cortical neurons incubated in a medium previously saturated with $95 \% \mathrm{~N}_{2}$ and $5 \% \mathrm{CO}_{2}$ for 20 min and containing the following: $116 \mathrm{~mm} \mathrm{NaCl}, 5.4 \mathrm{~mm} \mathrm{KCl}, 0.8 \mathrm{mM} \mathrm{MgSO}_{4}, 26.2 \mathrm{~mm} \mathrm{NaHCO}_{3}$, $1 \mathrm{mM} \mathrm{NaH}_{2} \mathrm{PO}_{4}, 1.8 \mathrm{~mm} \mathrm{CaCl}_{2}, 0.01 \mathrm{~mm}$ glycine, and $0.001 \% \mathrm{w} / \mathrm{v}$ phenol red; afterward, cells were placed in a hypoxic chamber for $3 \mathrm{~h}$ (Billups 
Rothemberg) $\left(37^{\circ} \mathrm{C}, 5 \% \mathrm{CO}_{2}\right.$, and $95 \% \mathrm{~N}_{2}$ ) (Sisalli et al., 2014). To terminate OGD, neurons were removed from the hypoxic chamber and placed in a normal medium for $24 \mathrm{~h}$ of RX. For PC, neurons were exposed to $30 \mathrm{~min}$ of $\mathrm{OGD}$, as described above, and then placed in a normal medium. Twenty-four hours after PC, cultures were again subjected to OGD for $3 \mathrm{~h}$ followed by $24 \mathrm{~h}$ of RX. Twenty-four hours after transfection with pKCRH-NCX1, pKCRH, siNCX1, and MS siNCX1 cells were subjected to OGD/RX or PC+OGD/RX. MS-275 $(1 \mu \mathrm{M})$ was added at the end of OGD for $2 \mathrm{~h}$, whereas C646 $(20 \mu \mathrm{M})$ was added to the medium 30 min before $\mathrm{PC}$ and throughout the $\mathrm{PC}$ phase.

\section{$q R T-P C R$ analysis}

First-strand cDNA and qRT-PCR were performed as previously described (Formisano et al., 2007). Using one-tenth of the cDNAs as a template, qRT-PCR was performed in a 7500-fast real-time PCR system (Applied Biosystems) by Fast SYBR Green Master Mix (cod 4385610; Applied Biosystems). Samples were amplified simultaneously in triplicate in one assay as follows: heating $2 \mathrm{~min}$ at $50^{\circ} \mathrm{C}$, denaturation $10 \mathrm{~min}$ at $95^{\circ} \mathrm{C}$, amplification and quantification 35 cycles of $15 \mathrm{~s}$ at $95^{\circ} \mathrm{C} ; 1 \mathrm{~min}$ at $60^{\circ} \mathrm{C}$ with a single fluorescence measurement. PCR data were collected using ABI Prism 7000 SDS software (Applied Biosystems). After PCR, products were electrophoretically separated on $1.5 \%$ agarose gels, and the bands were visualized with ethidium bromide and documented using a Gel Doc Imaging System (Bio-Rad). The data were normalized by hypoxanthine phosphoribosyl-transferase as an internal control. Differences in mRNA content between groups were calculated as normalized values by using $2^{-\Delta \Delta c t}$ formula, and results were tested for significance using the relative expression software tool (REST) (Formisano et al., 2007). The oligonucleotide sequences for NCX1 (forward 1716-1736 and reverse 3311-3292) (GenBank accession number NM_019268.3), NCX3 (forward 3229-3250 and reverse 1916-1899) (GenBank accession number NM_078620.1), and hypoxanthine phosphoribosyl-transferase (forward 444-467 and reverse 528-507) (GenBank accession number NM_078620.1) were performed as previously described (Pignataro et al., 2011).

\section{Western blotting}

For Western blot analysis, cells (or tissues) were collected in ice-cold lysis buffer (Formisano et al., 2013) containing anti-protease mixture (P8340 Sigma). For HDAC1, HDAC2, and acetyl-histone H3 expression, proteins $(50 \mu \mathrm{g})$ were separated on $12 \%$ SDS polyacrylamide gels, whereas for NCX1, NCX3, Sp1, Sp3, Sp4, REST, HIF-1 and p300 expression, proteins $(100 \mu \mathrm{g})$ were separated on $8 \%$ SDS-polyacrylamide gels. Both were transferred onto Hybond ECL nitrocellulose membranes (GE Healthcare). Membranes were first blocked with $5 \%$ nonfat dry milk in $0.1 \%$ Tween 20 (Sigma) ( $2 \mathrm{~mm}$ Tris- $\mathrm{HCl}$ and $50 \mathrm{~mm} \mathrm{NaCl}, \mathrm{pH} 7.5$ ) for $2 \mathrm{~h}$ at room temperature. Then, they were incubated overnight at $4^{\circ} \mathrm{C}$ in the blocking buffer with the 1:1000 monoclonal antibodies against HDAC1 (5356) and HDAC2 (5113) (Cell-Signaling, EuroClone), p300 (sc-48343; Santa Cruz Biotechnology), HIF-1 (MAB5382; Millipore), and 1:2000 $\beta$-actin (A 4700; Sigma), either with the 1:1000 polyclonal antibodies against REST (Iannotti et al., 2013) and acetyl-histone H3 (06-866) (Millipore), NCX1 (p 11-13; Swant), NCX3 (Boscia et al., 2012), Sp1 (sc-14027), Sp3 (sc-644), or Sp4 (sc-645) (Santa Cruz Biotechnology). Finally, after incubation with primary antibodies, membranes were first washed with $0.1 \%$ Tween 20 and then incubated with secondary antibodies for $1 \mathrm{~h}$ at room temperature. The immunoreactive bands were detected with the ECL reagent (GE Healthcare). The optical density of the bands, normalized to $\beta$-actin, was determined by Chemi-Doc Imaging System (Bio-Rad).

\section{ChIP and re-ChiP assay}

Brain tissue and cortical neurons were processed into chromatin according to previous protocols (Formisano et al., 2007) with some modifications. Cells and tissues were cross-linked with $1 \%$ formaldehyde, and then reaction was stopped by adding glycine to a final concentration of $0.125 \mathrm{M}$. Brain tissue and cells were washed three times in cold PBS containing proteinase inhibitors and then collected in a buffer containing 50 mm Tris, pH 8.1, 1\% SDS, 10 mm EDTA, and anti-protease mixture. For cell and tissue samples, chromatin was fragmented by sonication into $200-500 \mathrm{bp}$ fragments (6 rounds for cells and 15 rounds for brain tissue of $10 \mathrm{~s}$ pulses at $50 \%$ of maximum potency) by a Bandelin Sonopuls HD 2070 ultrasonic homogenizer (Bandelin). Equal amounts of chromatin lysates ( $50 \mu \mathrm{g}$ for cells and $70 \mu \mathrm{g}$ for tissues) were incubated overnight with $5 \mu \mathrm{g}$ of antibody for Sp1 (sc-14027), Sp3 (sc-644), Sp4 (sc-645), p300 (sc-48343) (Santa Cruz Biotechnology), REST (Iannotti et al., 2013), acetyl-histone H4 (06-866), hypoxia inducible factor $1 \alpha$ (MAB5382) (Millipore), HDAC1 (5356), HDAC2 (5113) (CellSignaling, EuroClone), and RNA POL II (R1530; Sigma). Normal rabbit or mouse IgG was used as negative control. After immunoprecipitation, the DNA-histone complex was collected with $40 \mu \mathrm{l}$ of salmon sperm DNA/protein A or G-agarose beads (16-157, 16-201; Millipore). After rotating for $2 \mathrm{~h}$ at $4^{\circ} \mathrm{C}$ on a spinning wheel, the beads were washed once with each of the following buffers in the order shown: high-salt buffer (0.1\% SDS, 1\% Triton X-100, 2 mм EDTA, 20 mm Tris HCl, pH 8.1, 500 mM NaCl); low-salt buffer (0.1\% SDS, $1 \%$ Triton X-100, 2 mm EDTA, 20 mм Tris HCl, pH 8.1, $150 \mathrm{~mm} \mathrm{NaCl})$; LiCl buffer (0.25 M LiCl, $1 \%$ NP40, $1 \%$ deoxycholate, 1 mm EDTA, $10 \mathrm{~mm}$ Tris $\mathrm{HCl}, \mathrm{pH} 8.1$ ). They were then washed twice at room temperature with TE buffer ( 10 mM Tris, $\mathrm{pH} 8.1$, and $1 \mathrm{~mm}$ EDTA). The precipitated fragments were eluted with a buffer containing $1 \% \mathrm{SDS}$ and $0.1 \mathrm{M} \mathrm{NaHCO}_{3}$. DNA was analyzed by qRT-PCR using Fast SYBR Green Master Mix (cod 4385610; Applied Biosystems). In particular, DNA sequences/samples were heated for $2 \mathrm{~min}$ at $50^{\circ} \mathrm{C}$ and denatured for $10 \mathrm{~min}$ at $95^{\circ} \mathrm{C}$. Amplification and quantification, achieved after 35 cycles at $95^{\circ} \mathrm{C}$ for $30 \mathrm{~s}$, were followed by single fluorescence measurements for $1 \mathrm{~min}$ at $60^{\circ} \mathrm{C}$. The binding activity was graphically represented as the percentage of the total input of chromatin, and the results were analyzed using a previously described formula (Renthal et al., 2007). The following oligonucleotides were used for the amplification of immunoprecipitated DNA: ncxl-Br (I) forward $5^{\prime}$ CCGCTGGGGAAACCCCTGCC-3' and reverse 5' -GCGCTGCAACTT TTCTTTTGAACG-3', ncx1-Br (II) forward 5'-GGGTGCAGAAGAG AGCGCTGGC-3' and reverse 5' - GCACAAAGCGCGGCGGCCCG-3' and Neurotrophin-3 (NT3) (Ishimaru et al., 2007). For each amplification, melting curves and gel electrophoresis of the PCR product were used to verify their identities. Samples were amplified simultaneously in triplicate in one assay run. Re-ChIP experiments were performed to detect the simultaneous presence of Sp1 with HIF-1 and p300 or of Sp3 with REST, HDAC1, and HDAC2. Beads from the first ChIP analysis with anti-Sp1 and anti-Sp3 were incubated with an equal volume of 10 $\mathrm{nm}$ dithiothreitol at $37^{\circ} \mathrm{C}$ for $30 \mathrm{~min}$ and centrifuged at $12,000 \mathrm{rpm}$ for 1 min to elute DNA-bound proteins. Elution was repeated twice. The final elute was diluted 1:10 in lysis buffer containing a protease inhibitor mixture and reimmunoprecipitated with anti-REST, anti-HIF-1, antiHDAC1, anti-HDAC2, anti-p300 antibodies or IgG. ChIP and input DNA were analyzed with PCR: denaturation for $10 \mathrm{~min}$ at $95^{\circ} \mathrm{C}, 35$ cycles of $30 \mathrm{~s}$ at $95^{\circ} \mathrm{C}$; for $1 \mathrm{~min}$ at $60^{\circ} \mathrm{C}$; for $1 \mathrm{~min}$ at $72^{\circ} \mathrm{C}$. PCR products were then electrophoresed on a $1.5 \%$ agarose gel and stained with ethidium bromide. For ChIP and Re-ChIP experiments, we used ncx1-Br (II) primers because the amplified sequence of $\mathrm{ncx} 1-\mathrm{Br}$ contains the binding sites for REST ( $-18 / 1)$ (Formisano et al., 2013), HIF-1 (-331/-327 and $-164 /-160$ ) (Valsecchi et al., 2011), Sp1, and Sp3.

\section{Transient-transfection ChIP assay}

Cell culture and ChIP from SHSY-5Y cells was performed as described above. At $48 \mathrm{~h}$ after transfection, the cells were harvested by cross-linking with $1 \%$ formaldehyde, and ChIP was performed with antibodies for $\mathrm{Sp} 1, \mathrm{Sp} 3$, and IgG as negative control (data not shown). The input and the precipitated DNA was amplified using ncx1-Br forward (II) $5^{\prime}$ GGGTGCAGAAGAGAGCGCTGGC-3' and a LucNrev primer 5' - CCTTATGCAGTTGCTCTCC -3 .

\section{Electrophoretic mobility shift assay (EMSA)}

EMSA experiments were performed as previously described (Valsecchi et al., 2011). In particular, $5 \mu \mathrm{g}$ of nuclear extracts was incubated with double-stranded DNA oligonucleotides (PRIMM) labeled with cy5 at the $5^{\prime}$ termini of both strands. Sense strand sequences were as follows: Cy5Sp1 consensus sequence: 5'-ATTCGATCGGGGCGGGGCGAGC-3' (Ko et al., 1998; Ryu et al., 2003); ncx1-Sp1B: 5'-AGGAGGCG- 
a

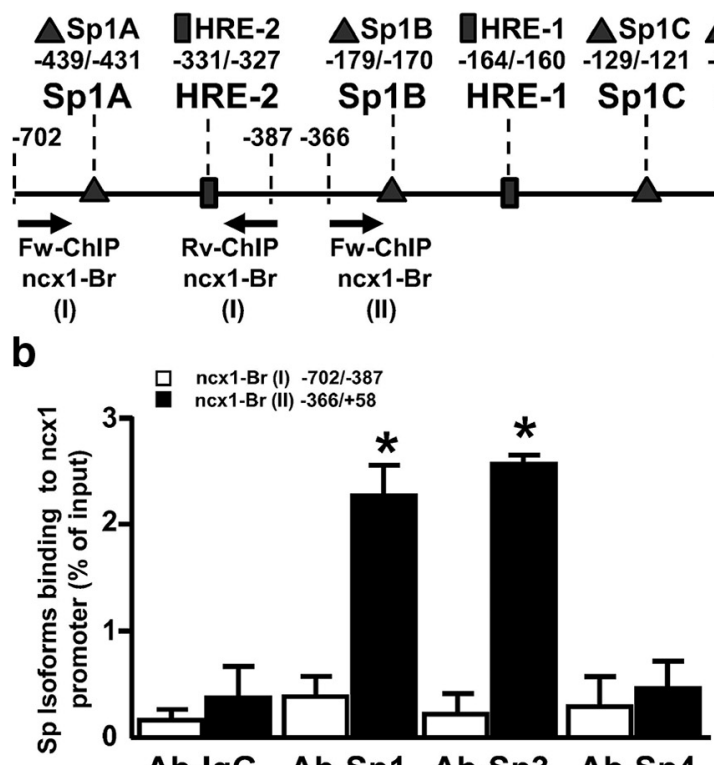

Ab-IgG Ab-Sp1 Ab-Sp3 Ab-Sp4
C

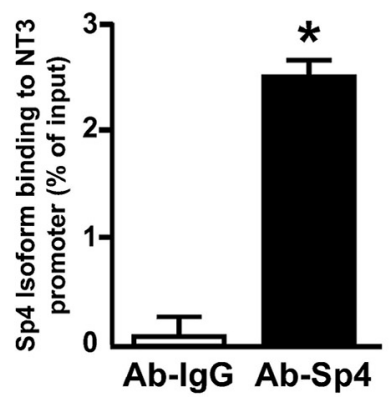

Figure 1. Transcription factors $S p 1$ and Sp3, but not Sp4, bind to $n c x 1$ brain promoter sequence from -366 to 58 . $a$, Map of the rat $n c x 1$ gene indicating location of Sp1, HIF-1 (HRE), REST (RE-1) sequences contained in distal [ $\mathrm{ncx} 1-\mathrm{Br}(\mathrm{I})]$ and proximal [ncx1-Br (II)] regions of $n c x 1$ brain promoter and of PCR primers used to detect the presence of specific DNA sequences in ChIP complexes. Triangles represent the 5 Sp 1 identified putative motifs in ncx1-Br, named Sp1A-E. Rectangles and square represent the 2 HRE sites and RE-1 site, respectively. $\boldsymbol{b}$, ChIP analysis of the $n \times x 1-B r(I)$ and ncx1-Br B (II) regions performed with anti-Sp1, anti-Sp3, and anti-Sp4. Anti-lgG was used as negative control. The binding activity of Sp1, Sp3, and Sp4 is graphically represented as the percentage of total input of chromatin DNA. C, ChIP analysis of the NT3 promoter region performed with anti-Sp4. Anti-lgG was used as negative control. The binding activity of $\mathrm{Sp} 4$ is graphically represented as the percentage of total input of chromatin DNA. ${ }^{*} p<0.05$ versus lgG. Each column represents the mean $\pm \operatorname{SEM}(n=3)$.

GCGGGCTGGGCT-3' and ncx1-Sp1Bmut: 5'-AGGAGGCTT CGGGCTGGGCT-3'; ncx1-Sp1C:5'-GGGCGAGCGGGCGGGGTGC $\mathrm{G}^{\prime}-3^{\prime}$ and ncx1-Sp1Cmut: 5'-GGGCGAGCGTTCGGGGTGCG-3'; ncx1Sp1D:5'-GGGAGGGAGGGGAGGGAGCG'-3' and ncx1-Sp1Dmut: $5^{\prime}-$ GGGAGGGATTGGAGGGAGCG-3'; ncx1-Sp1E:5'-GCCGCCCGG CCCCGGCCCTC-3' and ncx1-Sp1Emut: 5'-GCCGCCCGGCCC CTTCCCTC-3'. Each italicized base represents the mutated bases. For supershift experiments, $3 \mu \mathrm{g}$ of antibody against Sp1, Sp3, or Sp4 (Santa Cruz Biotechnology) was incubated on ice for $30 \mathrm{~min}$ before the addition of the probe. The reaction was run on a 5\% nondenaturing acrylamide gel at $200 \mathrm{~V}$ at $4^{\circ} \mathrm{C}$ in Tris borate-EDTA ( $30 \mathrm{~mm}$ Tris, $30 \mathrm{~mm}$ boric acid, $0.6 \mathrm{~mm}$ EDTA). The gels were scanned at $600 \mathrm{~V}$ on a Typhoon 9400 imager (GE Healthcare), using a green laser $(633 \mathrm{~nm})$ for excitation and a 670BP30 emission filter.

\section{Quantification of neuronal injury}

Neuronal injury was assessed by measurement of LDH efflux into the medium after OGD/RX or PC+OGD/RX. In neuronal cultures, LDH activity is correlated with the number of damaged cells in the medium (Koh and Choi, 1987). Cytosolic levels of LDH in the extracellular medium were measured with the LDH Cytotoxicity Kit (1000882 Cayman, DBA). Briefly, after induction of OGD/RX or PC+OGD/RX, the medium was removed and sampled for LDH content by measuring absorbance at 490 $\mathrm{nm}$ using a spectrophotometer BioPhotometer (Eppendorf). Cell lysate, prepared $1 \%$ Triton X-100, was used as a positive control and its value was considered $100 \%$.

\section{In vivo studies}

Experimental groups. Male Sprague Dawley rats (Charles River) weighing 250-300 g were housed under diurnal lighting conditions (12 h darkness/light). Experiments were performed according to the international guidelines for care and use of experimental animals of the European Community Council directive (86/609/EEC). All experiments were approved by the Institutional Animal Care and Use Committee of "Federico II" University of Naples, IT.
Transient focal ischemia and ischemic preconditioning. Transient focal ischemia was induced by suture occlusion of middle cerebral artery (MCA) in male rats with $1.5 \%$ sevoflurane, $70 \%$ $\mathrm{N}_{2} \mathrm{O}$, and 28.5\% $\mathrm{O}_{2}$ (Valsecchi et al., 2011) Achievement of ischemia was confirmed by monitoring regional cerebral blood flow through laser Doppler (PF5001; Perimed). Animals not showing cerebral blood flow reduction of at least $70 \%$, as well as those dying after ischemia induction, were excluded from the study. Rats were divided into four experimental groups: (1) shamoperated rats (CTL); (2) preconditioned rats (PC); (3) ischemic rats, subjected to tMCAO; and (4) preconditioned ischemic rats $(\mathrm{PC}+\mathrm{tMCAO})$. The sham-operated animals underwent the same experimental conditions, except that the filament was not introduced; in the ischemic group, the MCA was occluded for $100 \mathrm{~min}$; in the preconditioned ischemic group, rats were subjected to 30 min of tMCAO $72 \mathrm{~h}$ before $100 \mathrm{~min}$ of $\mathrm{tMCAO}$. The rat siRNAs used in ischemic and preconditioned ischemic rats were intracerebroventricularly administered $(1 \mu \mathrm{l})$ at concentrations of 20 $\mu \mathrm{M}$ for REST (Formisano et al., 2013), $3 \mu \mathrm{M}$ for HIF-1 (Valsecchi et al., 2011), and $10 \mu \mathrm{M}$ for Sp1, Sp3, HDAC1, HDAC2, and p300 (the catalog numbers are reported in Materials). For tMCAO and $\mathrm{PC}+\mathrm{tMCAO}$ experiments, intracerebroventricular injections were performed three times (i.e., 18 and $6 \mathrm{~h}$ before and $6 \mathrm{~h}$ after ischemia induction) and 24, 18, and $6 \mathrm{~h}$ before ischemic preconditioning induction. All animals were killed $24 \mathrm{~h}$ after $100 \mathrm{~min}$ tMCAO. Rectal temperature was maintained at $37 \pm 0.5^{\circ} \mathrm{C}$ with a thermostatically controlled heating pad, and a catheter was inserted into the femoral artery to measure arterial blood gases before and after ischemia (Rapid Laboratory 860, Chiron Diagnostic). All surgical procedures were performed under an operating stereomicroscope.

\section{Statistical analysis}

The data were evaluated as mean \pm SEM. Statistically significant differences among means were determined by ANOVA followed by StudentNewman-Keuls test. The threshold for statistical significance data was set at $p<0.05$.

\section{Results}

\section{$\mathrm{Sp} 1$ and $\mathrm{Sp} 3$ bind to a specific region of $\mathrm{ncx} 1-\mathrm{Br}$} promoter sequence

Because Sp1 and Sp3 both recognize the GC-rich sequences known as GC boxes (Isomura et al., 2005), we searched for Sp1 sequences at the level of the ncxl-Br promoter (GenBank accession no. U95138) and subjected the ncx1-Br sequence to a computational prediction of transcriptional factors using the database TF SEARCH, version 1.3 (Cassimere et al., 2009). As shown in Fig. $1 a$, five binding sites, named Sp1A-E, were identified within the ncxl-Br sequence at $-439 /-431,-179 /-170$, $-129 /-121,-111 /-104$, and $-67 /-58$ from the transcriptional start site. All these sequences were characterized by the TF search threshold score, a parameter of sequence identity, $>85.0$. To prove a direct association of $\mathrm{Sp}$ transcription factors with the ncx1-Br promoter in the nuclear environment, we performed ChIP assays on extracts from cortical neurons that basally express Sp1, Sp3 (Ryu et al., 2003), and Sp4 (Ishimaru et al., 2007). To this aim, we divided ncxl-Br into two different fragments, termed ncx1-Br (I) (-702/-387) and ncx1-Br (II) (-366/58), and experiments were performed using specific primers recog- 
a

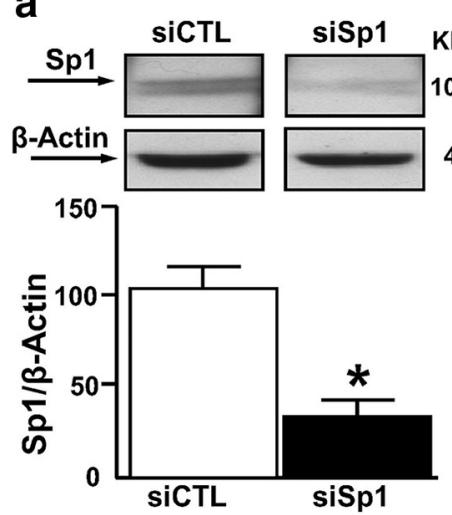

d

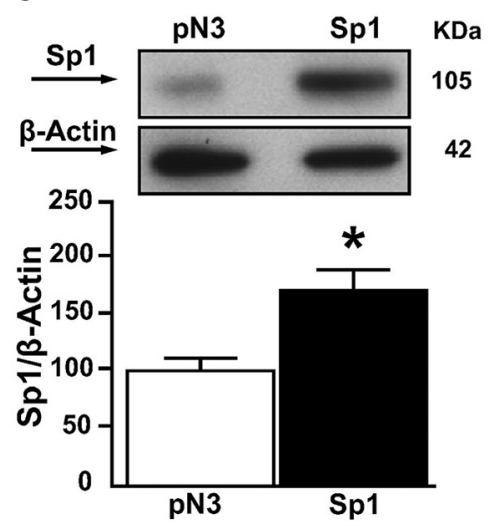

b

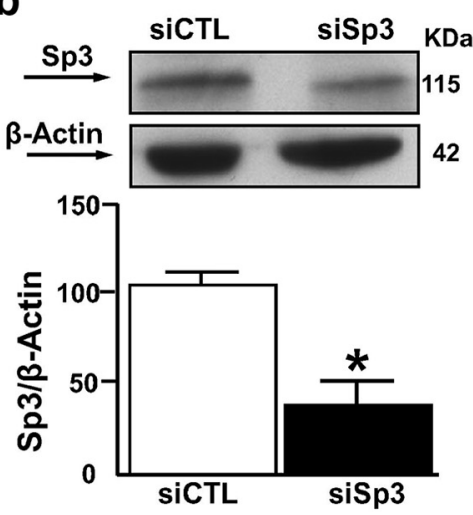

e

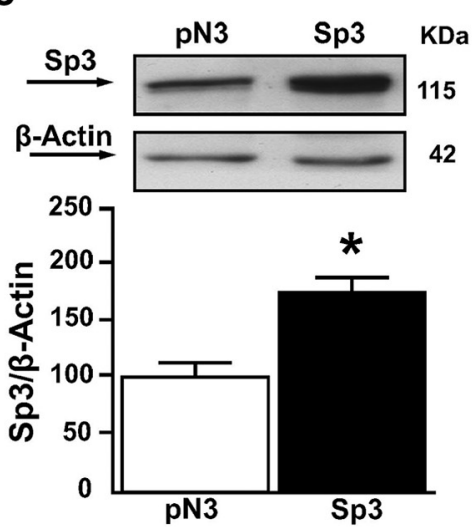

c

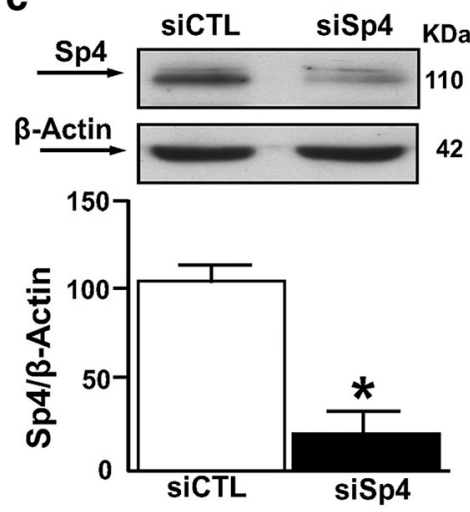

f

Figure 2. Cortical neurons transfected with siRNAs or constructs for Sp1, Sp3, and Sp4. $\boldsymbol{a}-\boldsymbol{c}$, Representative WB and quantification of Sp1, Sp3, and Sp4 protein expression in neurons after treatment with siCTL, siSp1, siSp3, and siSp4. $\boldsymbol{d}-\boldsymbol{f}$, Representative WB and quantification of Sp1, Sp3, and Sp4 protein expression in neurons after transfection with empty vector (pN3), and after Sp1, $\mathrm{Sp} 3$, and Sp4 overexpression. Each column represents the mean $\pm \mathrm{SEM}(n=3) .{ }^{*} p<0.05$ versus respective siCTL or $p N 3$.

nizing these two parts of the ncxl-Br promoter. As shown in Fig. $1 b$, when chromatin was precipitated with Sp1, Sp3, and Sp4 antibodies, ncxl-Br (II), but not ncx1-Br (I), was amplified with Sp1 and Sp3 antibodies, compared with control IgG. Importantly, no signal was detected with the Sp4 antibody in the ncxl-Br (I) and ncxl-Br (II) fragments (Fig. 1b), whereas it was able to bind its known target gene neurotrophin-3 (NT3) (Ishimaru et al., 2007) in cortical neurons (Fig. 1c). This result suggests that Sp4 does not bind to the ncxl-Br promoter and that only the ncx1-Br (II) sequence is important for Sp1 and Sp3 binding in cortical neurons.

\section{Sp1 and Sp3 have an opposite effect on $n c x 1$ gene promoter} activity, mRNA, and protein expression

To evaluate the effect of Sp transcription factors on the $n c x 1$ gene promoter activity (evaluated by luciferase assay), as well as mRNA and protein expression levels, neurons were silenced by specific siRNAs, namely, siSp1, siSp3, and siSp4. These were able to decrease Sp1, Sp3, and Sp4 protein expression by 68\%, 63\%, and $70 \%$, respectively (Fig. $2 a-c$ ). In particular, for luciferase experiments, we used a pGL3 construct containing the $5^{\prime}$ flanking region upstream of the brain $n c x 1$ transcriptional start site $(+1)$, named short ncxl promoter (pGL3-ncx1), already used in a previous study (Valsecchi et al., 2011). This construct contained the native Sp1 consensus sequences from B to E, which are present in the sequence of ncx1-Br (II) fragment. As shown in Figure $3 a-c$, Sp1 silencing reduced $n c x 1$ gene promoter activity, mRNA levels ( $24 \mathrm{~h}$ after the treatment), and protein expression (48 h after treatment) by $45 \%, 48 \%$, and $37 \%$, respectively. By contrast, $\mathrm{Sp} 3$ silencing increased $n c x 1$ gene promoter activity, mRNA levels ( $24 \mathrm{~h}$ after treatment), and protein expression $(48 \mathrm{~h}$ after the treatment) by $68 \%, 65 \%$, and $53 \%$, respectively. The concomitant silencing of Sp1 and Sp3 or the knockdown of Sp4 did not affect the ncxl gene promoter, mRNA levels, or protein expression, compared with cells transfected with siCTL. To further confirm the role of $\mathrm{Sp}$ transcription factors in modulating NCX1 expression, cortical neurons were transfected with constructs overexpressing Sp1, Sp3, and Sp4 (Fig. $2 d-f$ ). Neurons overexpressing Sp1 showed an increase in $n c x 1$ gene promoter activity, mRNA levels ( $24 \mathrm{~h}$ after the treatment), and protein expression ( $48 \mathrm{~h}$ after the treatment) by $64 \%, 77 \%$, and $61 \%$, respectively. By contrast, $\mathrm{Sp} 3$ overexpression decreased ncx1 gene promoter activity, mRNA levels ( $24 \mathrm{~h}$ after the treatment), and protein expression ( $48 \mathrm{~h}$ after the treatment) by $76 \%, 58 \%$, and $42 \%$, respectively. The concomitant overexpression of Sp1 and Sp3 or Sp4 transfection alone did not affect the $n c x 1$ gene promoter, mRNA levels, or protein expression, compared with control (Fig. 3d-f). To identify the functional Sp1 sequences within the $n c x 1$ promoter, the Sp1 binding sites B-E were mutated in the pGL3-ncxl construct by site-directed mutagenesis. Thus, four different luciferase reporter constructs (pGL3-ncx1/ Sp1 B mut, pGL3-ncx1/Sp1 C mut, pGL3-ncx1/Sp1 D mut, and pGL3-ncx1/Sp1 E mut; Fig. 4a) were generated and cotransfected into cortical neurons with an expression plasmid of Sp1 or Sp3 (Fig. $4 b, c$ ). Interestingly, the cells transfected with the three constructs pGL3-ncx1/Sp1C-E mut significantly reduced the increase of luciferase activity induced by Sp1 overexpression by $30 \%$ (Fig. 4b). By contrast, transfection of the three constructs in 


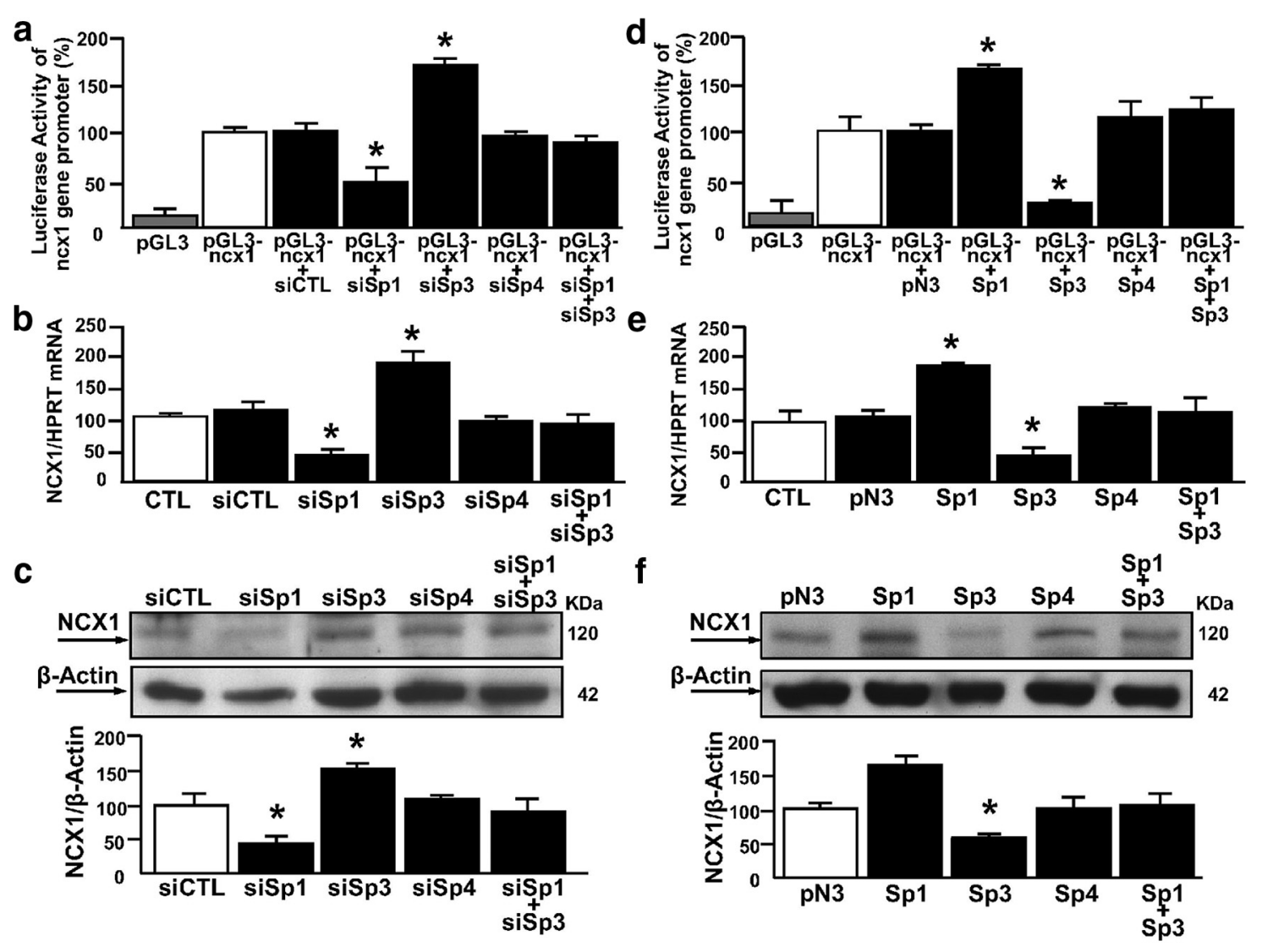

Figure 3. $S p 1$ is a transcriptional activator, whereas $S p 3$ is a transcriptional repressor of $n c x 1$ in cortical neurons. $\boldsymbol{a}-\boldsymbol{c}$, Luciferase assay of $n c x 1-B r$, qRT-PCR, and representative WB with quantification of NCX1 under control conditions (CTL) and after treatment with siCTL, siSp1, siSp3, siSp4, and in combination with siSp1 and siSp3 $(n=4)$. Each column represents the mean \pm SEM. ${ }^{*} p<0.05$ versus $p G L 3 n c x 1$, siCTL. $\boldsymbol{d}-\boldsymbol{f}$, Luciferase assay of $n c x 1-\mathrm{Br}$, qRT-PCR, and representative WB with quantification of NCX1 under control conditions (CTL) and after transfection with pN3 or overexpression of Sp1, Sp3, Sp4, and after combination of Sp1 and Sp3 $(n=3)$. Each column represents the mean \pm SEM. ${ }^{*} p<0.05$ versus pGL3 ncx1, pN3.

cells overexpressing Sp3 significantly reverted by 35\% Sp3decreased ncxl luciferase activity (Fig. 4c). Under both experimental conditions, mutation of Sp1 sequence B (pGL3-ncx1/Sp1 B mut) had no effect on $n c x 1$ transcriptional activity (Fig. $4 b, c$ ). Interestingly, in neurons overexpressing Sp1 or Sp3, transfection of pGL3-ncx1/Sp1 CDE construct containing mutations of all three Sp1 sites on ncxl-Br sequence, further reduced $n c x 1$ promoter-luciferase activity by $65 \%$ or increased it by $85 \%$, respectively, compared with pGL3-ncxl alone (Fig. $4 b, c)$. Because the ncxl-Br (II) fragment contains four (Sp1B-E) of the five putative Sp1 binding elements identified, EMSA experiments were performed to determine which of these Sp1 sites were involved in the binding with Sp1 and Sp3 proteins. These experiments were conducted in SH-SY5Y cell lines that have been already used to study the binding of Sp transcription factors on specific gene promoter sequence (Formisano et al., 2015a). Therefore, nuclear extracts from SH-SY5Y were incubated with a $5^{\prime}$-Cy5 fluorescent double-stranded oligonucleotide (Cy5-Sp1 consensus sequence), which specifically binds $\mathrm{Sp} 1$ and $\mathrm{Sp} 3$ as previously reported (Ko et al., 1998; Ryu et al., 2003). As shown in Figure $4 d$, lane 2 protein binding to the Cy5-Sp1 consensus sequence oligonucleotide produced two major closely migrating complexes (as indicated by the arrowheads). Interestingly, only the unlabeled oligonucleotides of ncx1/Sp1C-E sites competed for binding of both protein complexes (Fig. $4 d$, lanes 7, 8, 11, 12, 15 , and 16); however, this competition did not occur in the presence of excess mutated probes (Fig. $4 d$, lanes 9, 10, 13, 14, 17, and 18). Furthermore, as shown in Figure $4 d$ (lanes 3-6), the excess of ncx $1 /$ Sp1 B probes wild-type partially competed with Cy5-Sp1 consensus sequence, whereas the mutated were not able to modify the intensity of the doublet bands protein/DNA complexes. Moreover, the addition of antibodies against Sp1 and Sp3 was able to decrease the appearance of the upper and lower band of the formed complexes, respectively (Fig. $4 d$, lanes 19 and 20). Furthermore, EMSA experiments performed with fluorescent probes containing ncx $1 / \mathrm{Sp} 1 \mathrm{C}$ or $\mathrm{ncx} 1 / \mathrm{Sp} 1 \mathrm{D}$ or $\mathrm{ncx} 1 / \mathrm{Sp} 1 \mathrm{E}$ sequences showed the formation of specific DNA-protein complexes (Fig. $4 e-g$, lanes 1 ), that completely diminished in the presence of an excess of unlabeled probes (Fig. $4 e-g$, lanes 2), but not in the presence of an excess of mutated probes (Fig. $4 e-g$, lanes 3). This suggests that mutations of ncx1-Sp1C-E sites at these positions alter binding of proteins to the ncxl-Br promoter sequence. Interestingly, incubation of the nuclear extract with an anti-Sp1 and anti-Sp3 decreased the intensity of the upper and lower band for ncx1-Sp1 C (Fig. 4e, lanes 4 and 5), ncx1-Sp1D (Fig. $4 f$, lanes 4 and 5), and ncxl-Sp1E sites (Fig. $4 g$, lanes 4 and 5 ), indicating that the binding of Sp1 and Sp3, detected by the upper and lower band, was inhibited by the antibodies. Notably, experiments with antibody against Sp4 were not able to modify both bands of the complex formed between nuclear extracts and the probes (Fig. $4 c-e$, lane 7). To further confirm that $\mathrm{Sp} 1$ and Sp3 bind the ncx1-Sp1C-E sequences as suggested by EMSA, SHSY-5Y cells were cotransfected with plasmid containing the wild-type ncx1-Br promoter sequence (pGL3-ncxl) or the luciferase reporter constructs: pGL3-ncx1/Sp1 C mut, pGL3-ncx1/ Sp1 D mut, pGL3-ncx1/Sp1 E mut, and pGL3-ncx1/Sp1 CDE 
a

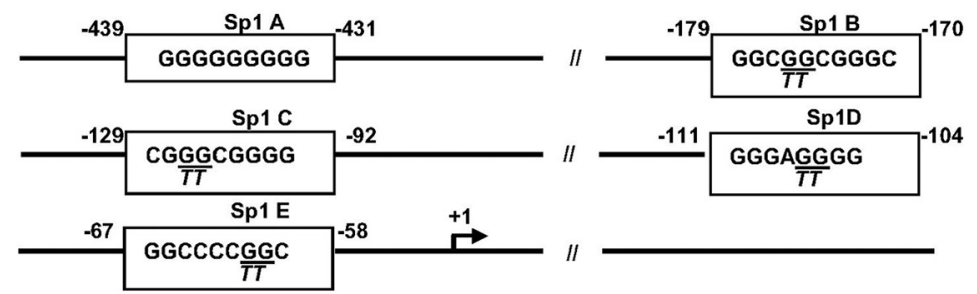

b

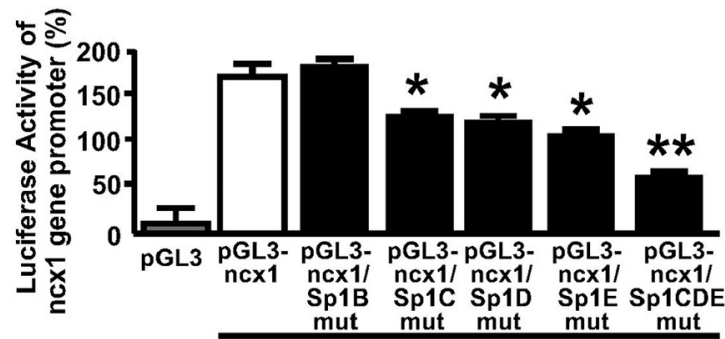

d
C

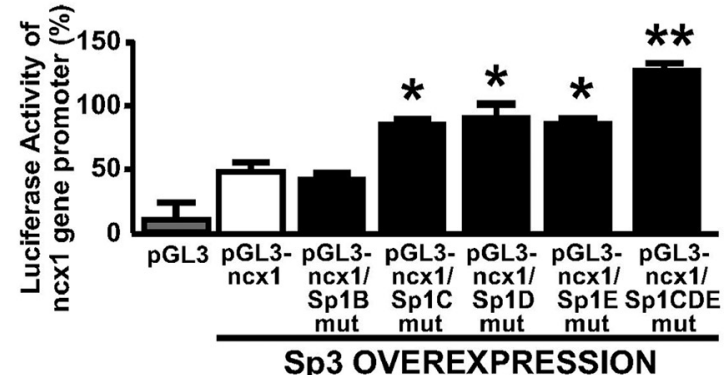

Sp3 OVEREXPRESSION

Probe: Cy5-Sp1 consensus sequence

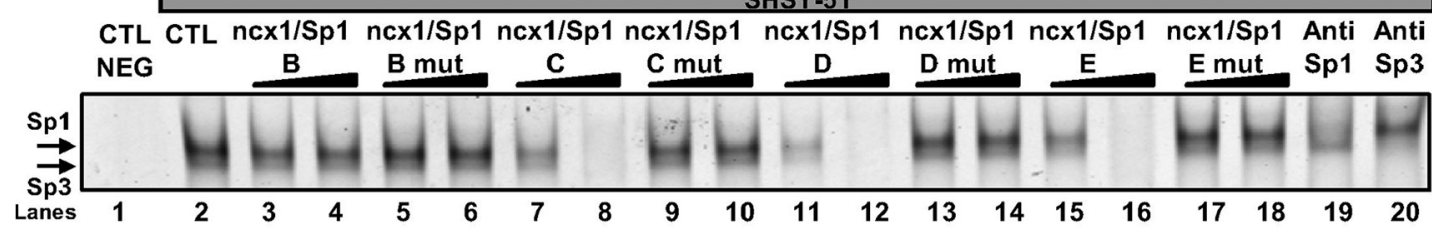

e

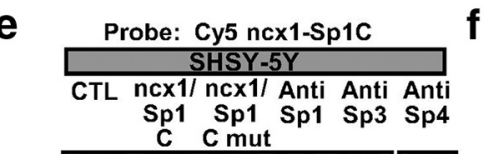
f

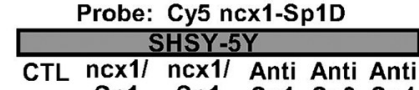
CTL ncx1/ ncx1/ Anti Anti Anti $\begin{array}{cc}\text { Sp1 } & \text { Sp1 } \\ \text { D } & \text { D mut }\end{array}$
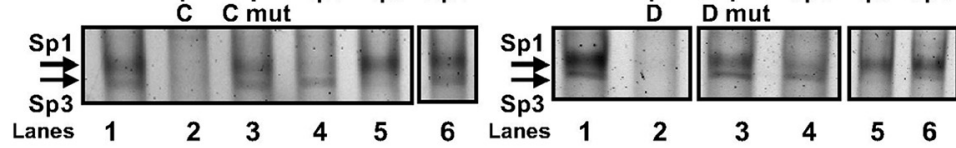

h

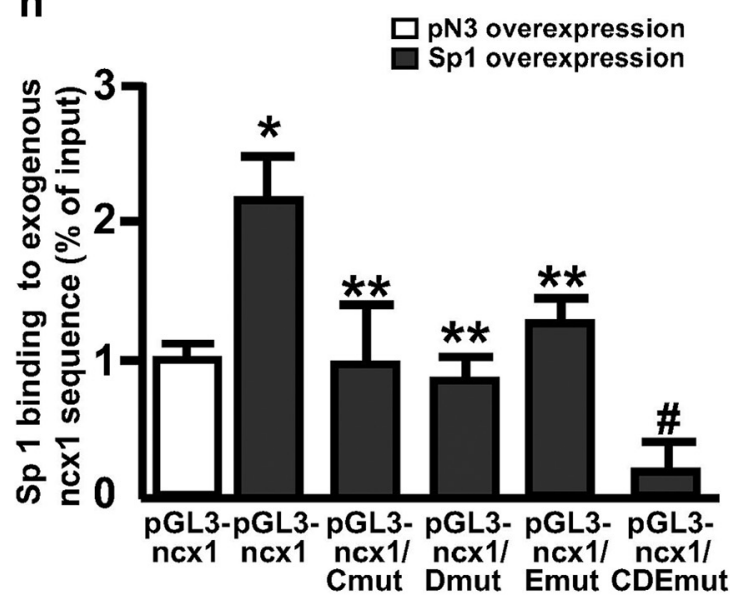

i

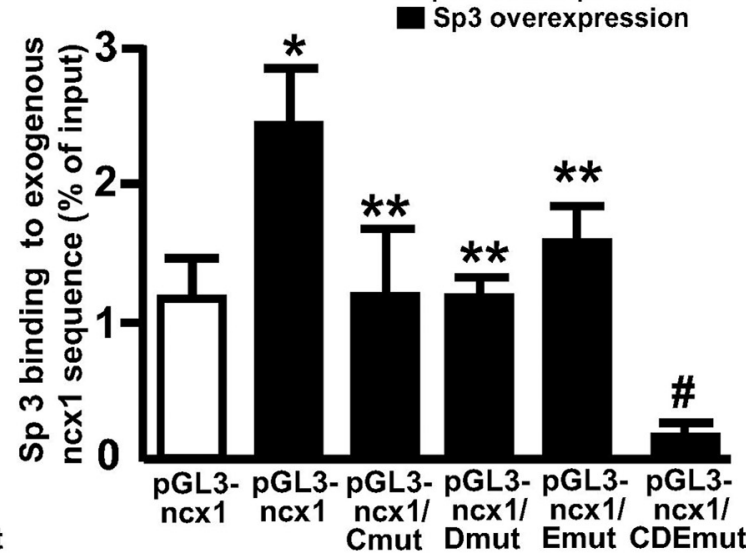

Figure 4. Effect of Sp1 and Sp3 on the transcriptional activity of ncx1-Br after site-directed mutagenesis of the putative Sp1 sites and analysis of their binding on ncx1-Br sequence. $\boldsymbol{a}$, The core consensus sequences of the five putative SP1A-E sites are boxed, and the locations relative to the reported transcription start site are separately numbered. Mutated nucleotides of the particular sequences are underlined, and the replaced nucleotides are shown in italics below the wild-type sequences. The bent arrows indicate the reported transcription start site. $\boldsymbol{b}, \boldsymbol{c}$, Cortical neurons transiently overexpressing Sp1 or Sp3 were cotransfected with pGL3-ncx1 or pGL3-ncx1/Sp1Bmut, pGL3-ncx1/Sp1Cmut, pGL3-ncx1/Sp1Dmut, pGL3-ncx1/Sp1Emut, and pGL3-ncx1/Sp1CDEmut constructs. Twenty-four hours after transfection, neurons were lysed in $1 \times$ passive lysis buffer. Lysates were analyzed for luciferase activity. Luciferase activity was expressed as firefly-to-renilla ratio. Each column represents the mean \pm SEM $(n=4) .{ }^{*} p<0.05$ vs pGL3-ncx1. ${ }^{* *} p<0.05$ versus all. $\boldsymbol{d}$, EMSA was performed incubating Cy5'-Sp1 consensus sequence probe without or with nuclear extracts from SH-SY5Y cells (CTL NEG and CTL, respectively, lanes 1 and 2). Competition experiments were performed with increasing molar excess (20-and 100-fold) of the unlabeled wild-type $n c x 1 / S p 1 B-E$ (ncx1/Sp1B, lanes 3 and 4; ncx1/Sp1C, lanes 7 and 8; ncx1/Sp1D, lanes 11 and 12; ncx1/Sp1E, lanes 15 and 16 ) and the mutant ncx1/Sp1B-E probes (ncx1/Sp1B, lanes 5 and 6; $n c x 1 / S p 1 C$, lanes 9 and 10; ncx1/Sp1D, lanes 13 and 14; ncx1/Sp1E, lanes 17 and 18). Antibodies specific for Sp1 and Sp3 were added to the EMSA reaction as indicated (lanes 19 and 20$)$. $\boldsymbol{e}-\boldsymbol{g}$, Nuclear extracts from SH-SY5Y cells were incubated with the Cy5'-tagged ncx1-Sp1C-E (CTL, lanes 1). Competition experiments were performed with increasing molar excess (100-fold) of the unlabeled wild-type $n c x 1 / S p 1 C-E(n c x 1 / S p 1 C-E$, lanes 2$)$ and the mutant ncx1/Sp1C-E (ncx1/Sp1C-E, lanes 3). Nuclear extracts were incubated in the presence of anti-Sp1, anti-Sp3, and anti-Sp4 (lanes 4-6). $\boldsymbol{h}, \boldsymbol{i}$, Chromatin was prepared from SHSY-5Y cells transiently transfected with Sp1, Sp3, and pN3 (empty vector) expressing plasmids and with (Figure legend continues) 

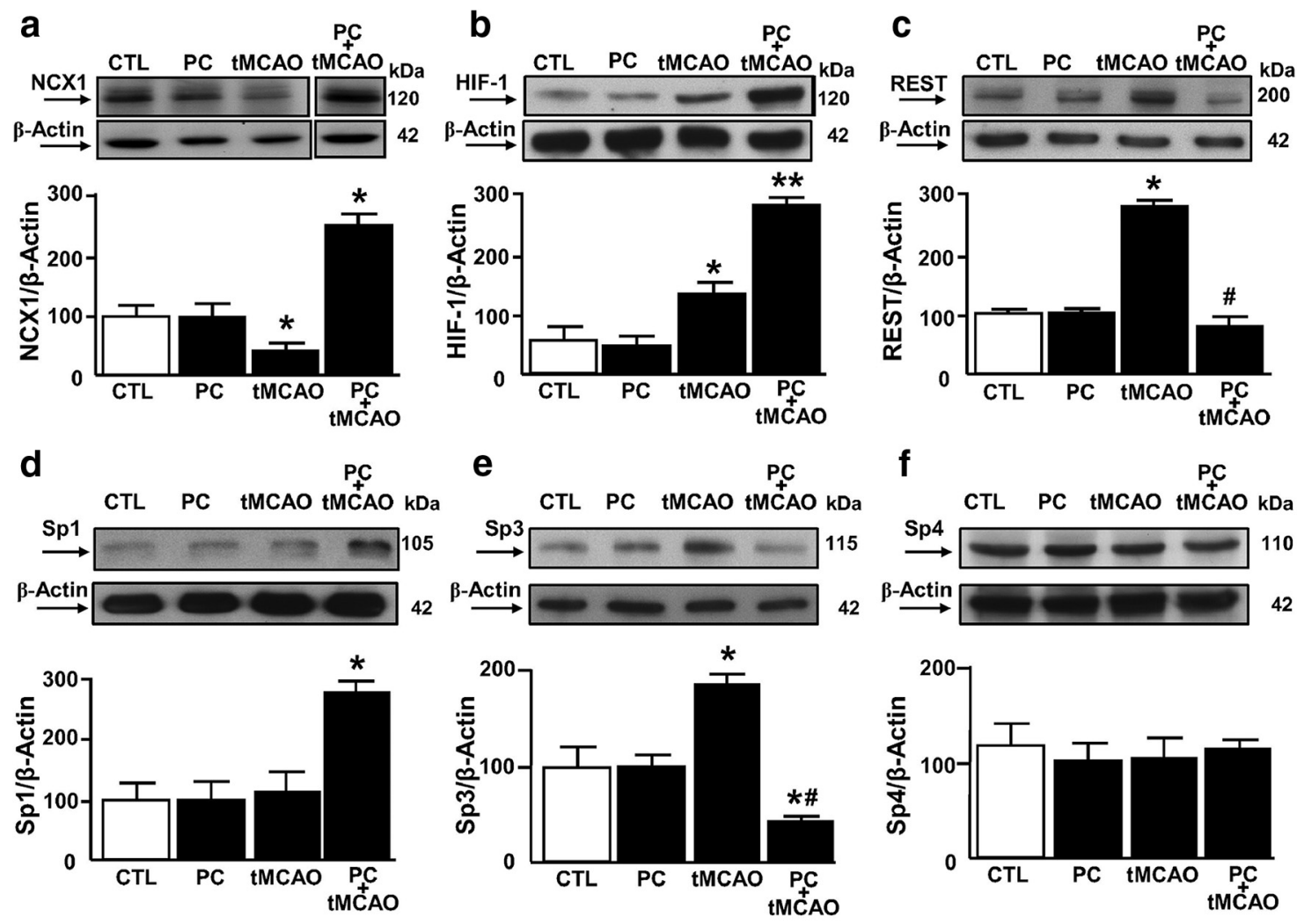

Figure 5. Effect of $\mathrm{MCA} 0$ and PC + tMCA0 on NCX1, HIF-1, REST, Sp1, Sp3, and Sp4 in the rat ipsilateral-temporoparietal cortex. $\boldsymbol{a}-\boldsymbol{f}$, Representative WB with quantification of NCX1, HIF-1, REST, Sp1, Sp3, and Sp4 protein expression in: (1) control group (CTL), (2) PC, (3) tMCA0, and (4) PC + tMCA0. Each column represents the mean \pm SEM ( $n=5$ animals for each column). ${ }^{*} p<0.05$ versus CTL. ${ }^{* *} p<0.05$ versus all. ${ }^{\#} p<0.05$ versus tMCA0.

mut, together with the Sp1- and Sp3-expressing plasmids to overexpress Sp1 and Sp3, respectively. Sp1 and Sp3 constructs were able to increase Sp1 and Sp3 protein expression by almost 50\%, respectively (data not shown). Then, transfected cells were subjected to ChIP assay with Sp1 and Sp3 antibodies. As shown in Figure $4 h, i$, exogenous wild-type chromatin was immunoprecipitated by the Sp1 and Sp3 and amplified using as forward primer an oligonucleotide recognized the ncxl-Br sequence [ncx $1-\mathrm{Br}$ forward (II)] and as reverse primer an oligonucleotide recognized specifically the luciferase gene of pGL3 construct (LucNrev). In particular, overexpression of Sp1 or Sp3 increased their binding on ncxl exogenous promoter sequence, compared with cells transfected with the empty vector $\mathrm{pN} 3$. By contrast, PCR product containing the mutated ncx1-Sp1C-E sequences was reduced, whereas transfection of a construct containing ncx1-Sp1C-E sites jointly mutated completely abolished Sp1 and Sp3 binding on ncxl exogenous sequence, compared with cells overexpressing Sp1 or Sp3 and transfected with pGL3-ncx1 con-

(figure legend continues.) the pGL3-ncx1 or pGL3-ncx1/Sp1Cmut, pGL3-ncx1/Sp1Dmut, pGL3-ncx1/Sp1Emut, and pGL3-ncx1/Sp1CDEmut constructs. Chromatin from transfected cells was immunoprecipitated with Sp1 and Sp3 antibodies. Exogenous DNA containing either the $n c x 1-B r$ fragment (-340/151, pGL3-ncx1) or the mutated Sp1C-E sequence alone or in combination (pGL3-ncx1/Sp1Cmut, pGL3-ncx1/Sp1Dmut, pGL3-ncx1/Sp1Emut, and pGL3-ncx1/ Sp1CDEmut constructs) was amplified using ncx1-Br forward II promoter-specific forward primer and a luciferase gene-specific reverse primer (LucNrev primer). The binding activity of Sp1 is graphically represented as the percentage of total input of chromatin DNA. ${ }^{*} p<0.05$ versus cells cotransfected with pN3 and pGL3-ncx1. ${ }^{* *} p<0.05$ versus cells cotransfected with constructs overexpressing Sp1 or Sp3 and pGL3-ncx1. ${ }^{\#} p<0.05$ versus all. Each column represents the mean $\pm \operatorname{SEM}(n=3)$. struct. Thus, Sp1 and Sp3 are efficiently recruited to the ncx1-br promoter sequence by binding ncx1-Sp1C-E sites. Together, these results demonstrate that $\mathrm{Sp} 1$ and $\mathrm{Sp} 3$ interact with the $\mathrm{ncx} 1-\mathrm{Br}$ promoter within three specific sequences, thereby increasing or decreasing its expression, respectively.

REST/Sp3 and HIF-1/Sp1 complexes colocalize on $n c x 1$ brain promoter after tMCAO and $\mathrm{PC}+\mathrm{tMCAO}$, respectively

The three Sp1 sequences we identified on the ncxl-Br promoter are located near the binding sites of both the ncxl transcriptional repressor REST and the ncxl transcriptional activator HIF-1. Whereas the former is responsible for NCX1 reduction in cerebral ischemia (tMCAO) (Formisano et al., 2013), the latter is responsible for NCX1 increase after ischemic preconditioning plus tMCAO (PC+tMCAO) (Valsecchi et al., 2011). The temporoparietal brain cortex has been chosen as a region of interest because after $\mathrm{TMCAO}$ ischemic damage it involves both striatum and cortex, which represent the brain areas irrigated by MCA. In particular, the temporoparietal cortex is a unique region because after tMCAO it includes the ischemic core, the area irreversibly damaged, and the ischemic penumbra, the area that can be still rescued from cell death (Barone et al., 1998; Pignataro et al., 2012) and intact tissue. In addition, the same cortical area is spared by the ischemic damage when a preconditioning stimulus is applied. Therefore, the processes triggered by preconditioning and able to modify the extent of ischemic brain lesion are usually evaluated in this area. Interestingly, Western blot analysis, performed in the ipsilesional-temporoparietal cortex of rats at $24 \mathrm{~h}$ after $\mathrm{PC}$ alone, $\mathrm{tMCAO}$, or $\mathrm{PC}+\mathrm{tMCAO}$ revealed that $\mathrm{PC}$ alone did not significantly modify the expression of NCX1, REST, HIF-1, Sp1, or Sp3 compared with CTL (Fig. $5 a-e$ ). On the con- 


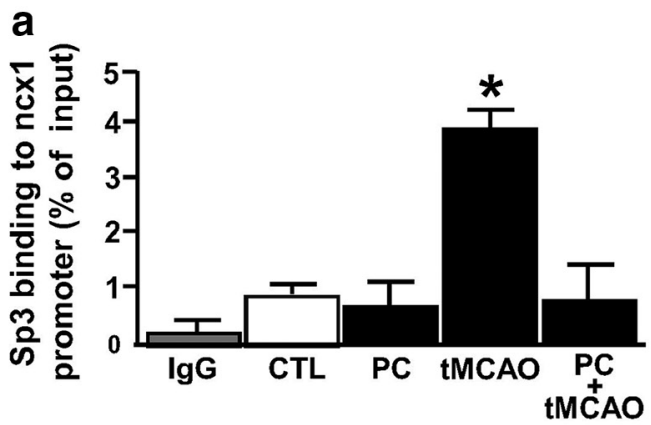

b

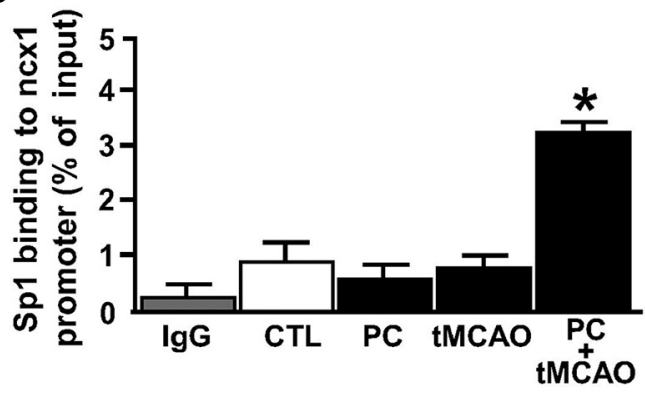

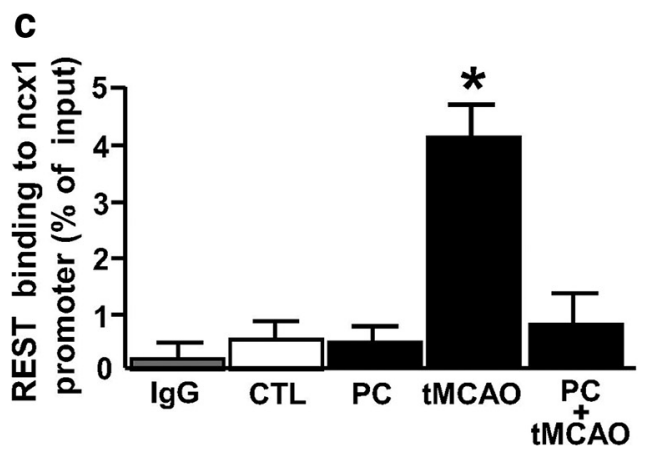

d
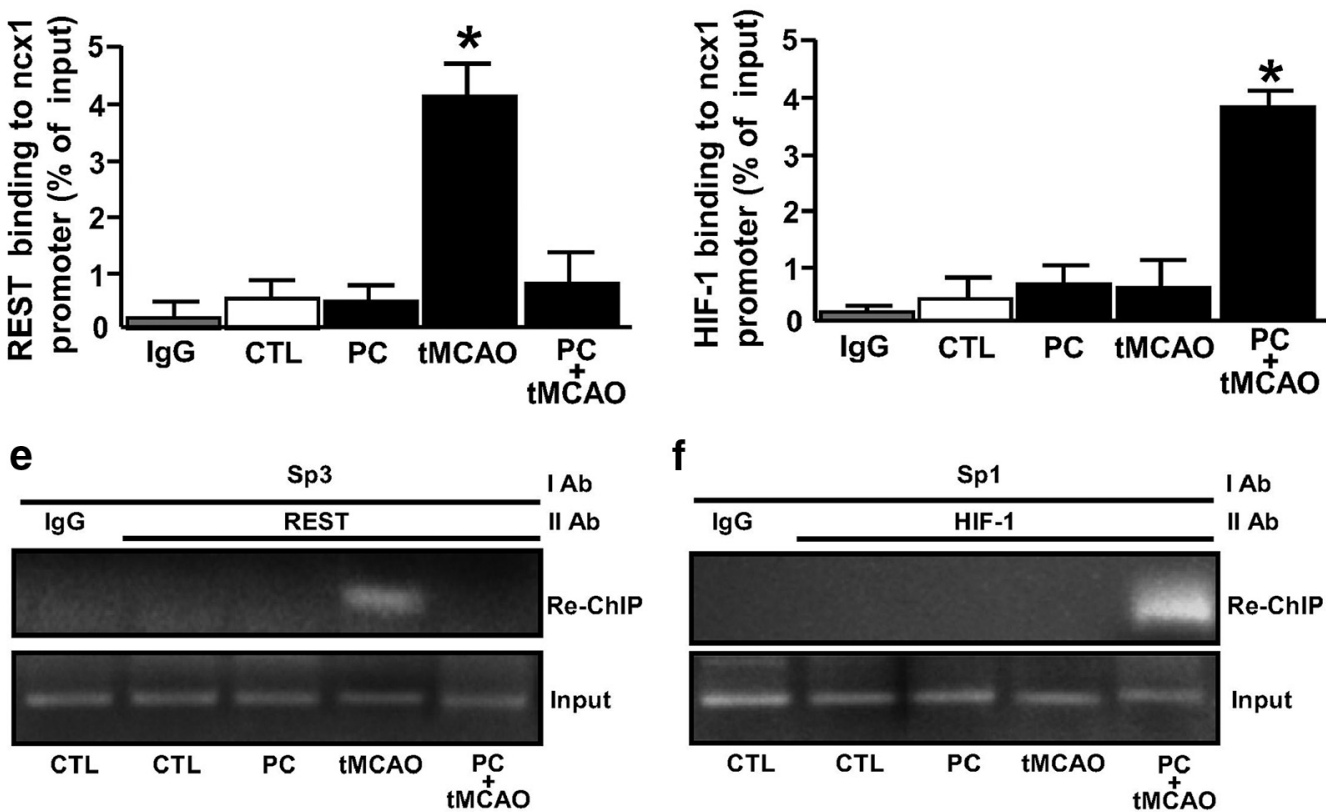

g

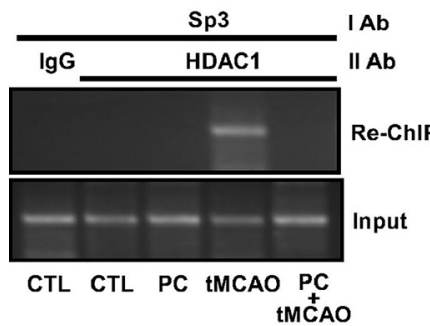

h
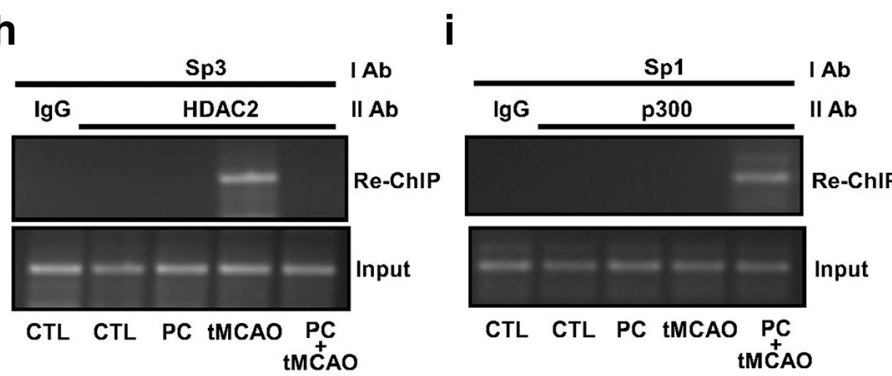

Figure 6. $\mathrm{TMCAO}$ and $\mathrm{PC}+\mathrm{tMCAO}$ rat models promote REST/Sp3/HDAC1/HDAC2 and HIF-1/Sp1/p300 colocalization on ncx1-Br in the ipsilateral-temporoparietal cortex, respectively. $\boldsymbol{a}-\boldsymbol{d}$, ChIP analysis of ncx1-Br in the ipsilateral-temporoparietal cortex in (1) CTL, (2) PC, (3) tMCA0, and (4) PC+ tMCA0. The binding activity of HIF-1, REST, Sp1, and Sp3 is graphically represented as the percentage of total input of chromatin DNA. Anti-IgG was used as negative control. Each column represents the mean \pm SEM $\left(n=6\right.$ animals for each column). ${ }^{*} p<0.05$ versus CTL. $e-i$, Re-ChIP analysis of ncx1-Br in the ipsilateral-temporoparietal cortex in (1) CTL, (2) PC, (3) tMCA0, and (4) PC+ tMCA0. Primary ChIP products for anti-Sp3 (I Ab) were subjected to re-ChIP with anti-REST, anti-HDAC1, and anti-HDAC2 (II Ab) $(\boldsymbol{e}, \boldsymbol{g}, \boldsymbol{h})$ but for anti-Sp1 (I Ab) were subjected to re-ChIP with anti-p300 (II Ab) (f, $\boldsymbol{i})$. Anti-lgG was used as negative control. The input DNA lane represents $5 \%$ of the precleared chromatin used in each ChIP reaction. The figure is representative of two independent experiments.

trary, tMCAO reduced NCX1 by $44 \%$ while simultaneously increasing HIF-1 by $75 \%$, REST by $180 \%$, and Sp3 by $100 \%$. However, it did not affect Sp1 (Fig. 5d). Finally, PC+tMCAO remarkably increased NCX1 by $140 \%$, HIF-1 by $450 \%$, and Sp1 by $180 \%$ compared with CTL, whereas it completely blocked tMCAO-induced REST and Sp3 increase, compared with tMCAO values (Fig. $5 a-e$ ). In all the above experimental conditions, $\mathrm{Sp} 4$ protein expression was not affected (Fig. $5 f$ ). To evaluate the possible interaction between REST and Sp3 and between HIF-1 and Sp1, their binding activity to the ncx1-Br sequence was measured in rats subjected to tMCAO and PC $+\mathrm{tMCAO}$. Inter- estingly, in rats subjected to cerebral ischemia, REST and Sp3 binding, but not HIF-1 and Sp1, increased, compared with CTL (Fig. $6 a-d$ ). On the contrary, whereas HIF-1 and Sp1 binding to the ncxl-Br sequence increased after PC + tMCAO, REST and Sp3 did not (Fig. $6 a-d$ ). We further conducted re-ChIP assay to test whether the transcriptional repressors REST and Sp3 or the transcriptional activators HIF-1 and Sp1 all colocalized on the ncx $1 \mathrm{Br}$ sequence during tMCAO and $\mathrm{PC}+\mathrm{tMCAO}$, respectively. Re-ChIP assay revealed that Sp3, REST, HDAC1, and HDAC2 (Fig. 6e,g, $h$, lanes 4), and Sp1, HIF-1, and p300 (Fig. 6f, $i$, lanes 5) were bound together on the ncxl promoter after tMCAO and 
a

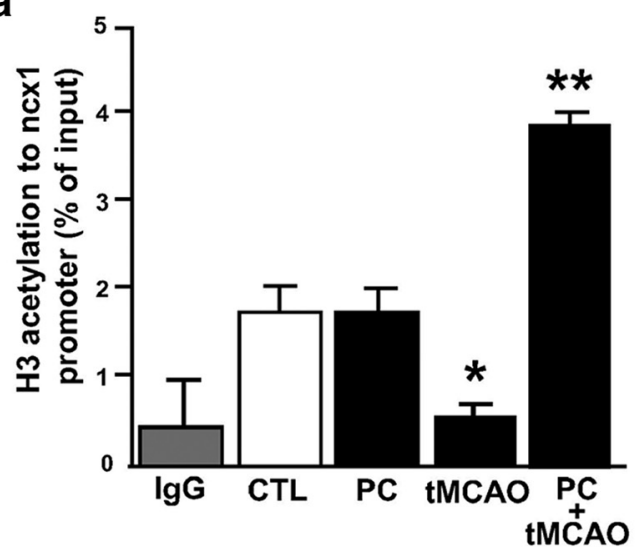

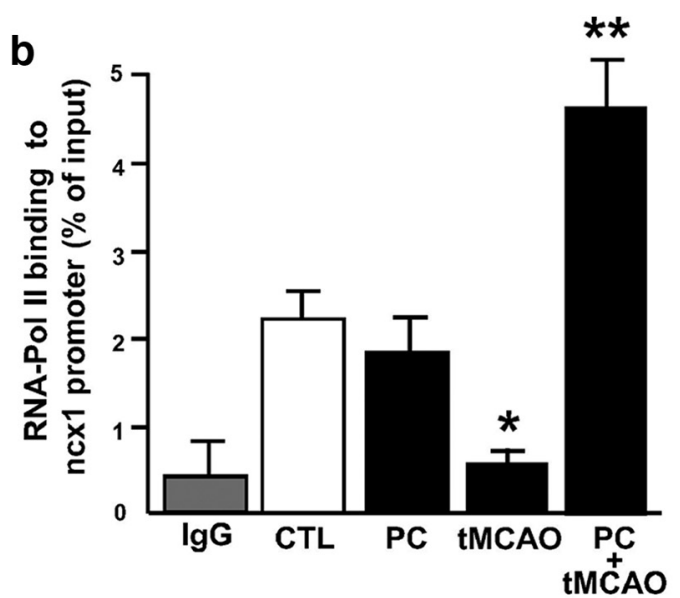

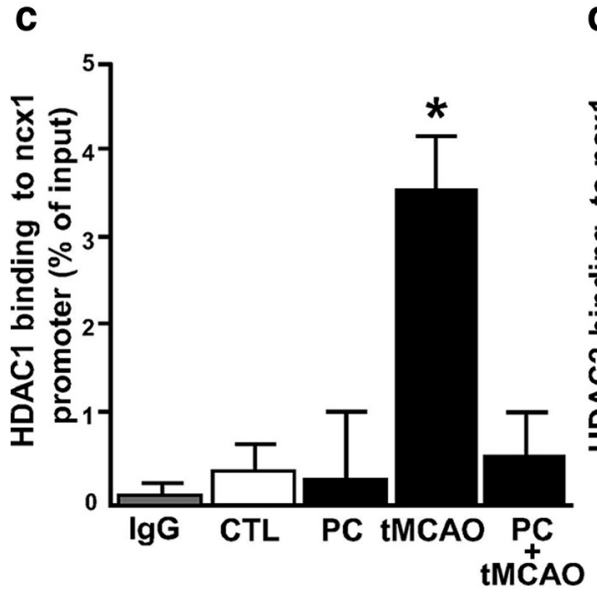

e

d

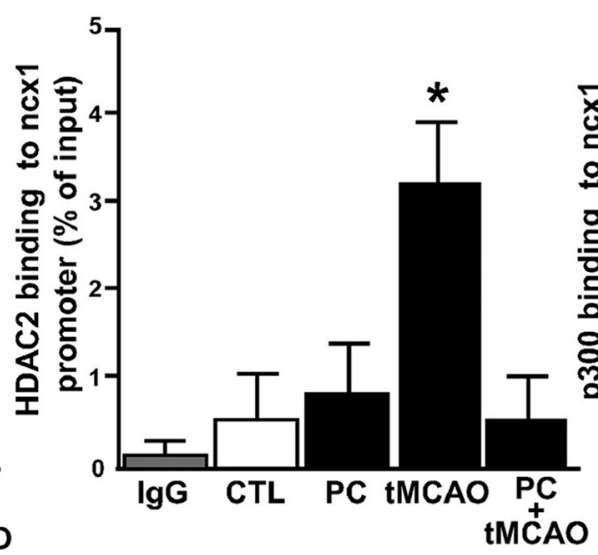

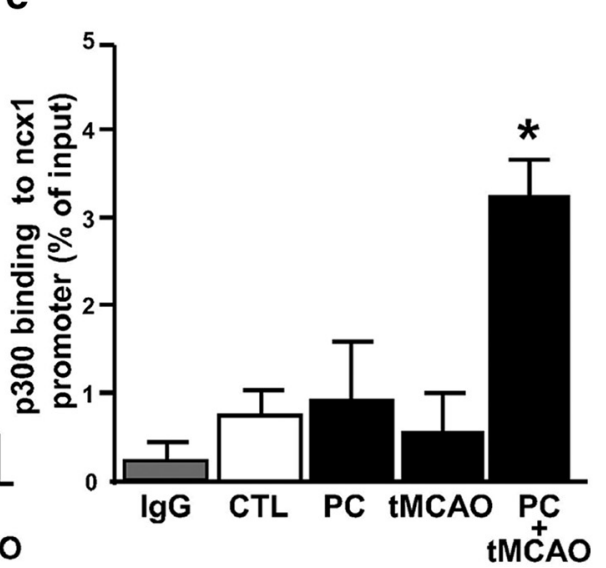

Figure 7. Effect of $\mathrm{MMCAO}$ and $\mathrm{PC}+\mathrm{tMCAO}$ rat models on $\mathrm{H} 3$ acetylation, RNA-POI II, HDAC1, HDAC2, and $\mathrm{p} 300$ binding to $\mathrm{ncx} 1-\mathrm{Br}$. $\boldsymbol{a}-\boldsymbol{e}$, ChIP analysis of ncx1-Br in the ipsilateral-temporoparietal cortex in (1) CTL, (2) PC, (3) tMCA0, and (4) PC + tMCA0. The binding activity of H3 acetyl, RNA-PoI II, HDAC1, HDAC2, and p300 is graphically represented as the percentage of total input of chromatin DNA. IgG was used as negative control. Each column represents the mean \pm SEM $\left(n=6\right.$ animals for each column). ${ }^{*} p<0.05$ versus CTL. ${ }^{* *} p<0.05$ versus all.

after $\mathrm{PC}+\mathrm{tMCAO}$, respectively. These results suggest that $\mathrm{Sp} 3$ REST, HDAC1, and HDAC2, and Sp1, HIF-1, and p300 form two functional complexes on the ncxl-Br sequence during tMCAO and $\mathrm{PC}+\mathrm{tMCAO}$, respectively.

Epigenetic remodeling of the ncx1-Br promoter by HDAC1 and HDAC2 after tMCAO and by p300 after PC+tMCAO

The transcription factors REST, HIF-1, Sp1, and Sp3 regulate their target genes by epigenetic modifications, such as acetylation (Won et al., 2002; Formisano et al., 2007; Azahri et al., 2012; Noh et al., 2012; Pawlus and $\mathrm{Hu}, 2013$ ). Thus, by performing ChIP assay, we evaluated the following: (1) the modification of the acetylated histone protein $\mathrm{H} 3$; (2) the binding of HDAC1, HDAC2, and histone acetyltransferase p300; and (3) the binding of RNA polymerase II (RNA-Pol II) on ncx1-Br promoter sequence in the ipsilesional-temporoparietal cortex of rats subjected to PC, tMCAO, and PC+ tMCAO and compared it with CTL. PC alone did not significantly modify the amount of the $n c x 1$ promoter associated with acetylated H3, RNA-Pol II, HDAC1, HDAC2, and p300 (Fig. 7a-e).

On the other hand, our results showed that tMCAO reduced the amount of the $n c x 1$ promoter associated with acetylated $\mathrm{H} 3$ and RNA-Pol II (Fig. 7a,b). Concomitantly, the same experimental condition increased the binding activity of HDAC1 and HDAC2 on the ncxl gene promoter (Fig. $7 c, d$ ), compared with CTL. After tMCAO, p300 binding on the $n c x 1-\mathrm{Br}$ promoter was absent (Fig. 7e). Interestingly, HDAC1 and HDAC2 did not bind to the ncxl-Br promoter in animals subjected to $\mathrm{PC}+\mathrm{tMCAO}$ (Fig. $7 c, d$ ). Contrarily, our results showed that PC+tMCAO increased not only the amount of ncxl-Br associated with acetylated $\mathrm{H} 3$, but also the binding activity of RNA-Pol II and p300 to the ncxl-Br promoter, compared with CTL (Fig. 7a,b,e). To better understand the role of REST, Sp3, HDAC1, and HDAC2 in tMCAO-induced NCX1 reduction, we evaluated the acetylation status of the ncxl-Br promoter, the $n c x 1$ gene level, and protein expression, after intracerebroventricular injection of siSp3, siREST, alone or in combination, and siHDAC1 and siHDAC2 in combination. In particular, siSp3, siHDAC1, and siHDAC2 were able to reduce protein expression by $80 \%, 75 \%$, and $81 \%$, respectively, whereas expression for siREST was already published (Formisano et al., 2013) (Fig. $8 a-c$ ). As shown in Figure $9 a-c$, tMCAO-induced ncxl-Br deacetylation. In addition, the $n c x 1$ gene and protein reduction were reverted when all the proteins were silenced, compared with CTL. Furthermore, tMCAOinduced Sp3 and REST binding to ncx $1-B r$ sequence was reverted when Sp3 and REST were silenced alone or in combination, compared with siCTL (Fig. 9d). Interestingly, in the same experimental conditions, tMCAO-induced ncx 3 gene and protein decrease was not reverted by siSp3, siREST, alone or in combination, and by double silencing for HDAC1 and HDAC2, compared with the CTL (Fig. 10a,b). Furthermore, we studied the role of HIF-1, Sp1, and p300 in the PC+tMCAO-induced NCX1 increase after in- 
tracerebroventricular injection of siSp1, siHIF-1, alone or in combination, and sip300. In particular, siSp1 and sip300 were able to reduce protein expression by $80 \%$ and $85 \%$ (Fig. $8 d, e$ ), respectively, whereas the decrease of protein expression obtained by siHIF-1 was already published (Valsecchi et al., 2011). Our results showed that hyperacetylation of histone $\mathrm{H} 3$ on the ncx1- $\mathrm{Br}$ promoter sequence, induced by $\mathrm{PC}+\mathrm{tMCAO}$, was reverted when we administered siSpl (Fig. 9e), siHIF-1, alone or in combination, and sip300 (Fig. 9e), compared with the CTL (Fig. 9e). Likewise, the $n c x 1$ gene and protein increase, induced by PC+tMCAO, was also reverted (Fig. 9f,g). In addition, $\mathrm{PC}+\mathrm{tMCAO}$-induced Sp1 and HIF-1 binding to ncx1-Br sequence was reverted when Sp1 and HIF-1 were silenced alone or in combination, compared with siCTL (Fig. 9h). Importantly, in the same experimental conditions, $\mathrm{PC}+\mathrm{tMCAO}$-induced ncx3 gene and protein increase was not reverted by silencing the above mentioned transcriptional factors, compared with the CTL (Fig. 10c,d).
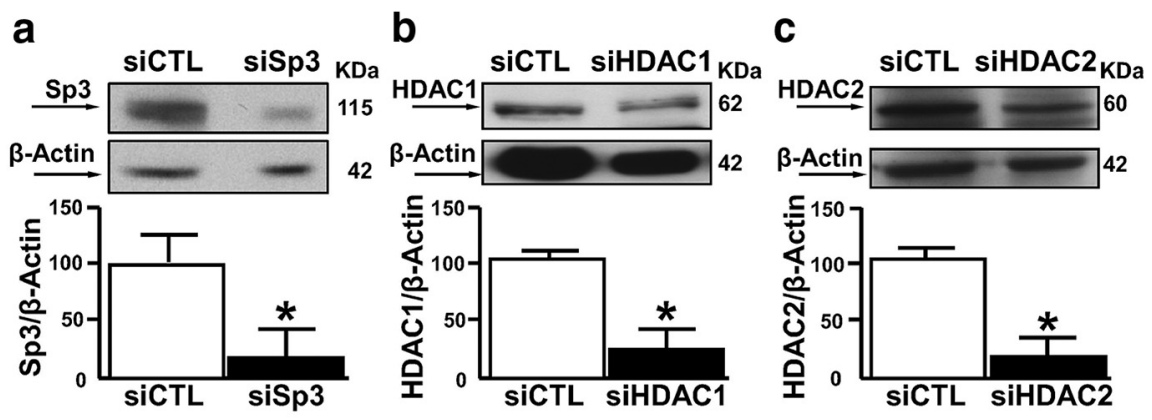

d
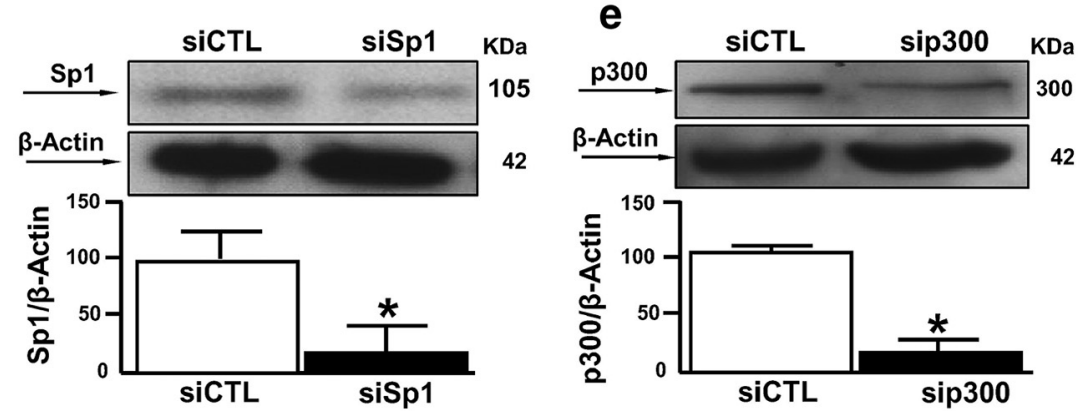

Figure 8. Sp1, Sp3, HDAC1, HDAC2, and p300 protein expression in rat brain after siRNA treatment. $\boldsymbol{a}-\boldsymbol{e}$, Representative Western blots of Sp3, HDAC1, HDAC2, Sp1, and P300 protein levels in the temporoparietal cortex of rats intracerebroventricularly treated with siSp3, siHDAC1, siHDAC2, siSp1, and siP300. Each column represents the mean \pm SEM $(n=3)$. ${ }^{*} p<0.05$ versus respective siCTL.

\section{Class I HDAC inhibitor MS-275 reduces neuronal cell death by increasing NCX1 expression during OGD/RX}

Considering that HDAC1 and HDAC2 belong to Class I histone deacetylases (Chuang et al., 2009), we evaluated the effect of the Class I HDAC inhibitor MS-275 (1 $\mu \mathrm{M})$ in cortical neurons exposed to OGD/RX (Lanzillotta et al., 2013; Formisano et al., 2015b). First, we validated the specificity of MS-275 to inhibit Class I HDAC by measuring the levels of the acetylated forms of histone H3 (indicating the activity of Class I) (Simonini et al., 2006; Galmozzi et al., 2013). Results showed that MS-275 increased histone $\mathrm{H} 3$ acetylation (Fig. 11a). In addition, MS-275 exerted a remarkable neuroprotective effect by preventing cell death during OGD/RX, an effect that was though counteracted by siNCX1. Interestingly, siNCX1 alone exacerbated the neuronal death induced by OGD/RX (Fig. 11b).

To identify the role of NCX1 in MS-275-induced neuroprotection, Western blot analysis was performed for NCX1 under the same experimental conditions. Furthermore, exposure of cortical neurons to OGD/RX+MS-275 induced an increase in NCX1 protein expression compared with the OGD/RX+vehicle (Fig. 11c). As expected, the MS-275-induced NCX1 increase was counteracted by siNCX1 (Fig. 11c).

\section{Hystone acetyl transferase p300 inhibitor C646 reverts PC-} induced neuroprotection by counteracting NCX1 increase We investigated whether PC could exert a neuroprotective effect in cortical neurons exposed to OGD/RX by increasing p300 and NCX1 expression. The specificity of C646 to inhibit hystone acetyl transferase p300 was validated by measuring the levels of the acetylated form of histone $\mathrm{H} 3$ (Federman et al., 2013). Results showed that C646 decreased histone $\mathrm{H} 3$ acetylation (Fig. 11d). In particular, in neurons exposed to PC+OGD/RX, the p300 inhibitor C646 (20 $\mu \mathrm{M})$ (Min et al., 2010), increased cell death compared with vehicle. Interestingly, NCX1 overexpression was able to counteract C646-induced neuronal death, compared with vec- tor (Fig. 11e). In addition, C646 prevented the increase in NCX1 in cortical neurons exposed to $\mathrm{PC}+\mathrm{OGD} / \mathrm{RX}$, an effect that was counteracted by NCX1 overexpression (Fig. 11f).

\section{Discussion}

This study has shown, for the first time, that NCX1 is epigenetically downregulated in brain ischemia by the REST/Sp3 complex and upregulated in brain ischemic preconditioning by the HIF1/Sp1 complex. Particularly, our results suggest that these proteins form two functional complexes on the ncx $1-\mathrm{Br}$ sequence in brain ischemia and in brain ischemic preconditioning. We showed that REST/Sp3-induced NCX1 downregulation after tMCAO $24 \mathrm{~h}$ and HIF-1/Sp1-induced NCX1 upregulation after $\mathrm{PC}+\mathrm{tMCAO} 24 \mathrm{~h}$ are associated with these transcriptional factors expression. Particularly, $24 \mathrm{~h}$ after tMCAO and $24 \mathrm{~h}$ after $\mathrm{PC}+\mathrm{tMCAO}$ was the first time points in which Sp3 (data not shown) and REST (Formisano et al., 2013) or HIF-1 (Valsecchi et al., 2011) and Sp1 (data not shown), respectively, were increased. Indeed, intracerebroventricular injections of siREST and siSp3, alone or in combination, in tMCAO, and of siHIF-1 and siSp1, alone or in combination, in $\mathrm{PC}+\mathrm{tMCAO}$ completely reverted the decreases and the increases, respectively, in NCX1 mRNA and protein levels. Previous studies have proposed that a crosstalk between Sp1, Sp3, and REST regulates the expression of some genes. For instance, hypoxia-induced expression of the regulation in development and DNA damage response (Redd1) gene is mediated by the coactivation of Sp1 and HIF-1 (Jin et al., 2007). Interestingly, in our study, we report, for the first time, that a crosstalk between $S p 1, S p 3$, and REST specifically regulates $n c x 1$ expression. In particular, whereas $\mathrm{Sp} 1$ activates the expression of REST target genes (Plaisance et al., 2005), Sp3 interacts with REST by binding to the GC box, thereby repressing the expression of mu opioid receptor (Kim et al., 2006). Moreover, within the rat ncx1-Br, we discovered five Sp1 motifs (Sp1A-E) located at $-439,-179,-129,-111$, and -67 from the transcriptional 

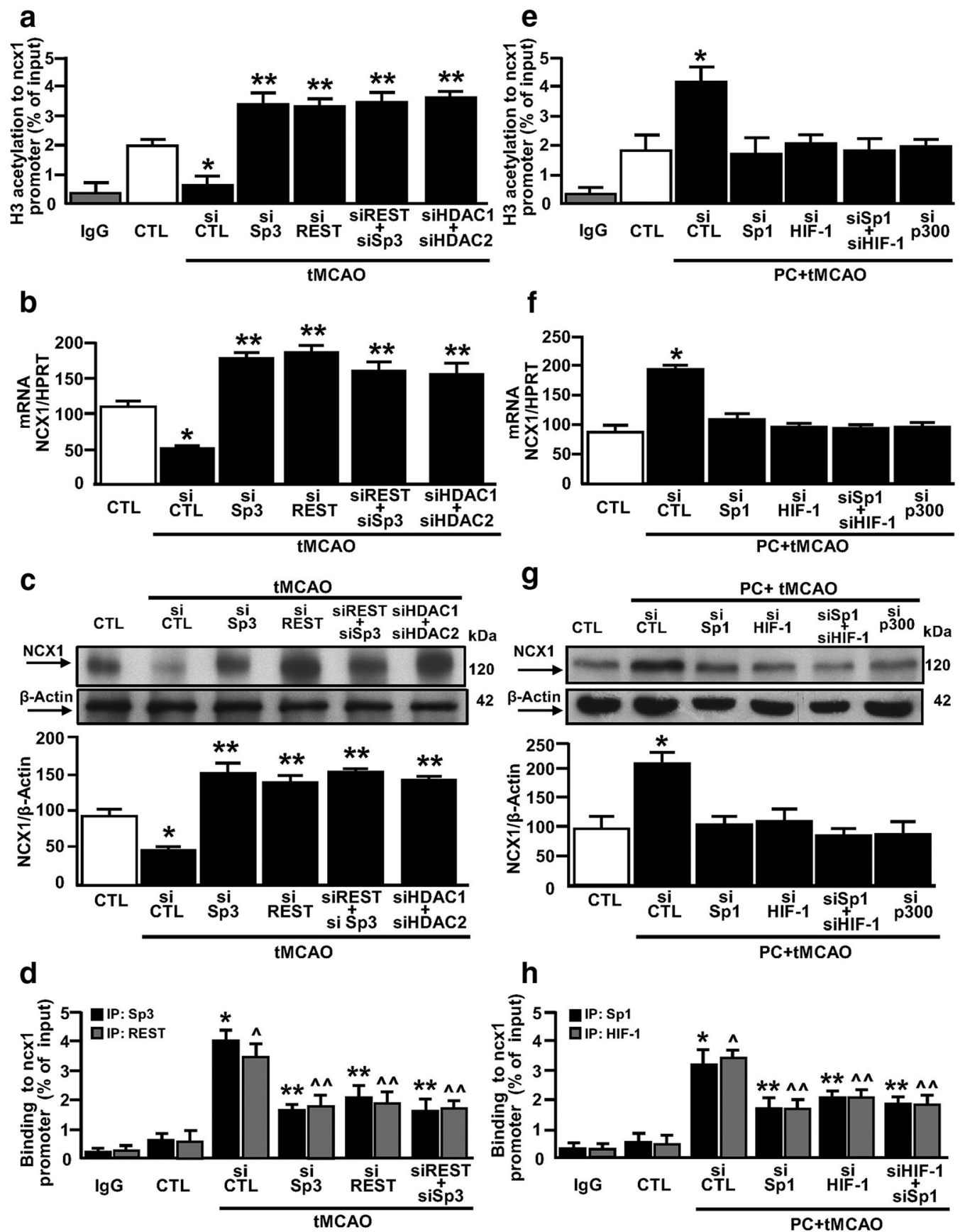

Figure 9. NCX1 is epigenetically modulated by Sp3/REST/HDAC1/2 complex in $T M C A 0$ and by Sp1/HIF-1/p300 in PC + TMCAO. $a$, ChIP analysis with anti-H3 acetyl of ncx1-Br in CTL and in $t M C A 0$ after intracerebroventricular injection of siCTL, siSp3, siREST, siREST + siSp3, and siHDAC1 + siHDAC2. IgG was used as negative control. Each column represents the mean \pm SEM $(n=5$ animals for each column). ${ }^{*} p<0.05$ versus (TL. ${ }^{* *} p<0.05$ versus all. $\boldsymbol{b}, \boldsymbol{c}$, qRT-PCR and representative WB with quantification of NCX1 in CTL and in $\mathrm{MCA0}$ after intracerebroventricular injection of siCTL, siSp3, siREST, siREST + siSp3, and siHDAC1 + siHDAC2. Each column represents the mean \pm SEM ( $n=6$ animals for each column). ${ }^{*} p<0.05$ versus CTL. ${ }^{* *} p<0.05$ versus all. $\boldsymbol{d}$, ChIP analysis with anti-Sp3 (black bars) and anti-REST (gray bars) of ncx1-Br in CTL and in TMCAO after intracerebroventricular injection of siCTL, siSp3, siREST, siREST + siSp3, and siHDAC1 + siHDAC2. IgG was used as negative control. Each column represents the mean \pm SEM $\left(n=6\right.$ animals for each column). ${ }^{*}, p<0.05$ versus CTL. ${ }^{*}, p p<0.05$ versus all. $e$, ChIP analysis with an anti-H3 acetyl of $n c x 1-B r$ in CTL and in PC + tMCA0 after intracerebroventricular injection of siCTL, siSp1, siHIF-1, siHIF-1 + siSp1, and sip300. Ig was used as negative control. Each column represents the mean \pm SEM $(n=$ 6 animals for each column). ${ }^{*} p<0.05$ versus (TL. $\boldsymbol{f}, \boldsymbol{g}$, qRT-PCR and representative WB with quantification of NCX1 in CTL and PC + tMCA0 after intracerebroventricular injection of siCTL, siSp1, siHIF-1, siHIF-1+ siSp1, and sip300. Each column represents the mean \pm SEM ( $n=6$ animals for each column). ${ }^{*} p<0.05$ versus CTL. $\boldsymbol{h}$, ChIP analysis with anti-Sp1 (black bars) and anti-HIF-1 (gray bars) of ncx1-Br in CTL and in PC + tMCA0 after intracerebroventricular injection of siCTL, siSp1, siHIF-1, and siHIF-1+ siSp1. IgG was used as negative control. Each column represents the mean \pm SEM ( $n=5$ animals for each column). ${ }^{*}, p<0.05$ versus CTL. ${ }^{* \wedge}{ }^{\wedge} p<0.05$ versus all.

start site, and indentified them as possible molecular determinants involved in Sp1 isoform-induced $n c x 1$ regulation. Furthermore, we found that, among the Sp family of transcription factors, $\mathrm{Sp} 1$ and $\mathrm{Sp} 3$, but not $\mathrm{Sp} 4$, bind to $\mathrm{ncx} 1-\mathrm{Br}$ in a very selective manner, as revealed by ChIP analysis. These results are in accordance with other studies showing that not all the genes containing GC boxes in their promoter are regulated by all Sp1 transcription factor isoforms (Lerner et al., 2002) and that some genes are target of Sp1 and Sp3, but not of Sp4 (Nguyen-Huynh and Schaffer, 1998; Khalil et al., 2008). Importantly, even though 
a
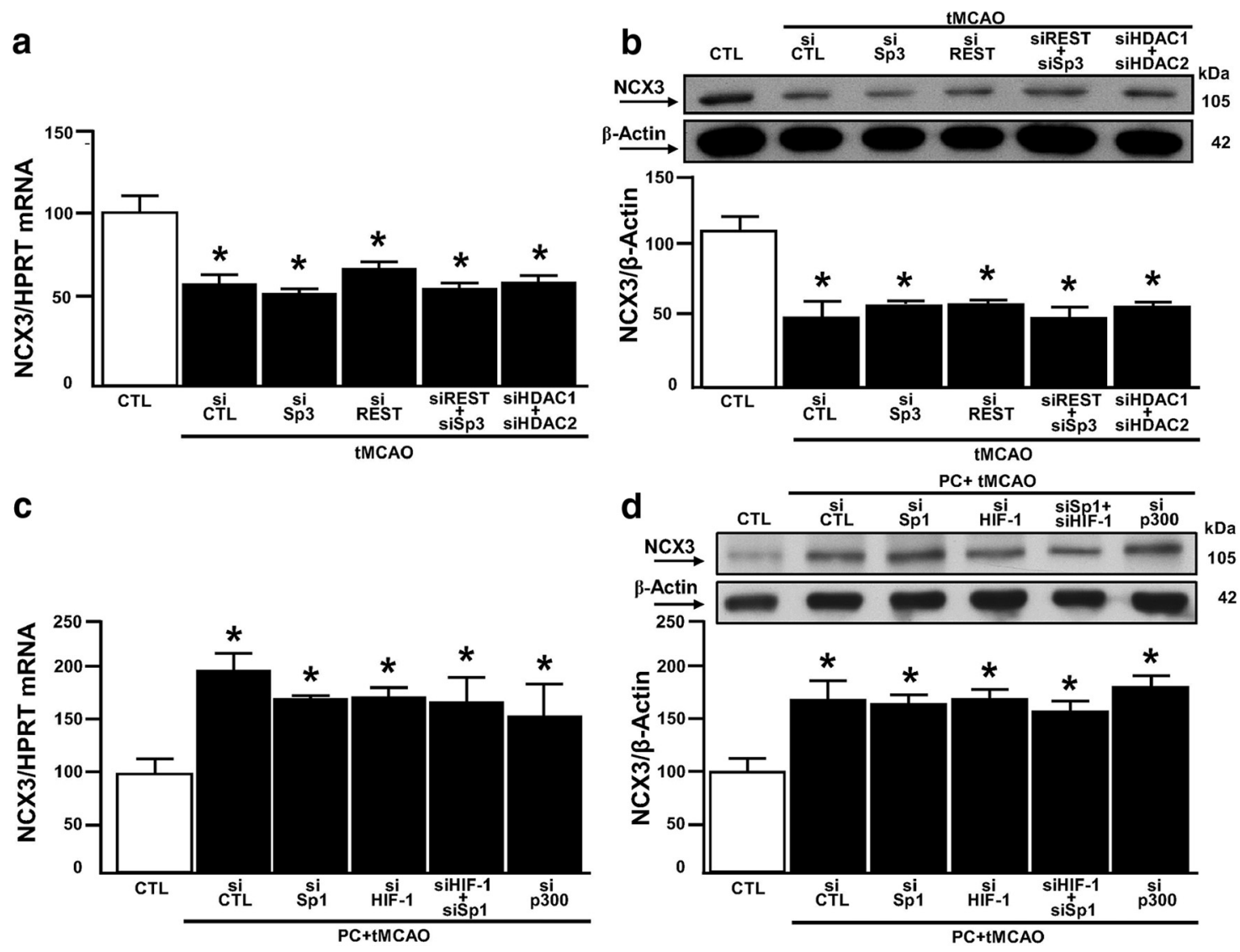

Figure 10. NCX3 is not modulated by the Sp3/REST/HDAC1/2 complex in $\mathrm{MCAO}$ and by Sp1/HIF-1/p300 in PC+ tMCA0, $\boldsymbol{a}, \boldsymbol{b}, \mathrm{qRT}-\mathrm{PCR}$ and representative WB with quantification of NCX3 in CTL and in $\mathrm{MCA} 0$ after intracerebroventricular injection of siCTL, siSp3, siREST, siREST + siSp3, and siHDAC1 + siHDAC2. Each column represents the mean \pm SEM $\left(n=5\right.$ animals for each column). ${ }^{*} p<$ 0.05 versus CTL. ${ }^{* *} p<0.05$ versus all. $\boldsymbol{c}, \boldsymbol{d}$, qRT-PCR and representative WB with quantification of NCX3 in CTL and PC + tMCA0 after intracerebroventricular injection of siCTL, siSp1, siHIF-1, siSp1+ siHIF-1, and sip300. Each column represents the mean \pm SEM ( $n=5$ animals for each column). ${ }^{*} p<0.05$ versus CTL.

Sp4 in mammals is predominantly expressed in tissues of neuronal origin (Lerner et al., 2005), regulating the developmental patterning of dendrites (Ramos et al., 2007), and has been linked to schizophrenia (Pinacho et al., 2011), our experiments show that $\mathrm{Sp} 4$ does not bind the ncxl-Br promoter sequence in cortical neurons. Conversely, our results on the regulation of NCX1 by Sp1 and Sp3 are in line with data showing that Sp1 and Sp3 regulate the transcription of target genes by binding to identical cognate DNA elements with similar affinities (Hagen et al., 1992). Indeed, transfection of specific siRNAs for Sp1 and Sp3 in cortical neurons produced a decrease or an increase, respectively, in the $n c x 1$ promoter activity, mRNA levels, and protein expression. These results demonstrate that $\mathrm{Sp} 1$ is an activator, whereas $\mathrm{Sp} 3$ is a repressor of $n c x 1$ transcription, a mechanism also reported for other Sp1 target genes (Stains et al., 2003). Notably, in the present paper, we identified three Sp1 binding sites (C-E) on ncx1-Br, which showed the highest promoter activity, and found that mutations at the level of the Sp1C-E sites in neurons overexpressing $\mathrm{Sp} 1$ and Sp3 could significantly reduce or increase, respectively, the activity of $n c x 1$ brain promoter, whereas Sp1B had no effect. As regard the Sp1-B site, because the binding to this putative Sp1 site of nuclear factors from SHSY-5Y cells is partially competed by the Cy5-Sp1 consensus sequence, we cannot exclude the possibility that other additional transcription factors recognizing GC elements different from Sp1 family (Carrasco-Serrano et al., 1998), such as the Early growth response protein 1 (Mora-López et al., 2008), may participate to bind such complexes. Accordingly, luciferase experiments show that $\mathrm{Sp} 1$ and $\mathrm{Sp} 3$ factors are not involved in the regulation of ncxl-Br promoter activity through the Sp1-B site. Importantly, as shown by ChIP, this effect was associated with an increase of Sp1 or of Sp3 binding on Sp1C-E sites, which was completely abolished when the three sequences were jointly mutated. Collectively, these results show that three of the five putative Sp1 elements present on the ncxl-Br sequence modulate the promoter activity of the $n c x 1$ gene. Indeed, studies report that global transcriptional repression upon ischemia is similarly reflected by a decrease in histone acetylation and that HDAC inhibition reduces ischemia-induced alterations in HDAC expression, thereby determining neuroprotection (Abel and Zukin, 2008; Noh et al., 2012). Consistently, data emerging from our study seem to suggest that both REST during ischemia and HIF-1 during preconditioning interfere with NCX1 gene expression through the participation of HDAC1, HDAC2, and p300. In particular, our ChIP analyses reveal that in brain ischemia REST and Sp3, together with the corepressors HDAC1 and HDAC2, are recruited to ncx1-Br, thus decreasing $\mathrm{H} 3$ acetylation, RNA-Pol II binding, and determining a reduction in ncxl mRNA and protein levels. Interestingly, $\mathrm{PC}+\mathrm{tMCAO}$ induces an increase in the abundance of ncxl-Br associated with acetylated $\mathrm{H} 3$, along with increases in RNA-Pol II, HIF-1, and p300 binding, thus determining an increase in NCX1 mRNA levels and protein expression. Furthermore ReChIP experiments using Sp3 as first antibody and REST, HDAC1, or HDAC2 as second antibody, or Sp1 as first antibody and HIF-1 or p300 as second antibody, further confirm that REST/Sp3/ HDAC1/HDAC2 and HIF-1/Sp1/p300 are present on ncx1-Br 


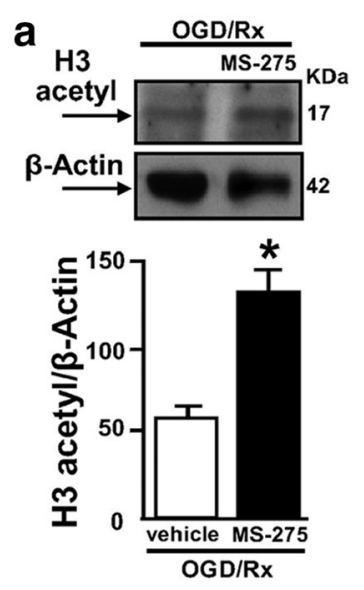

d

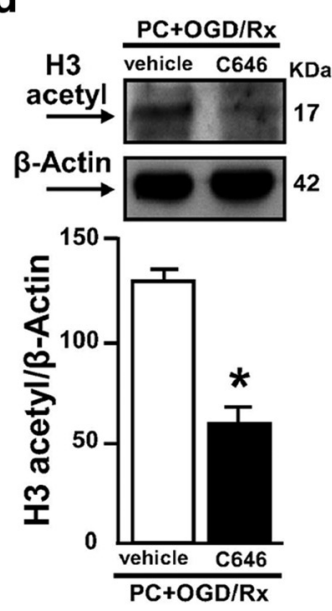

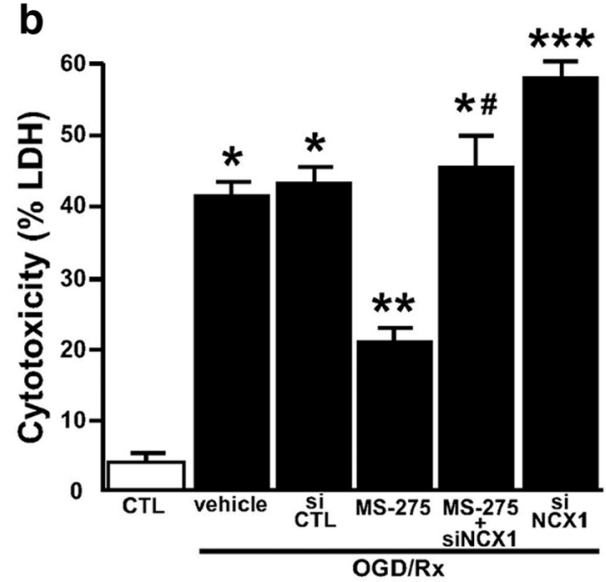

e

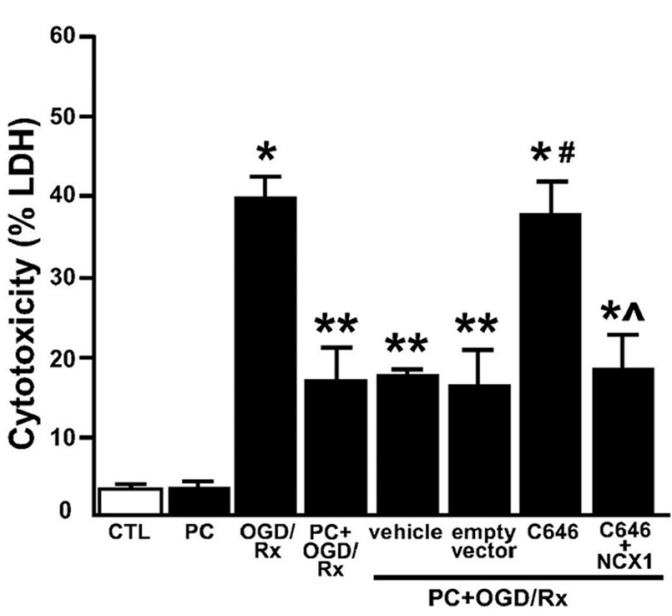

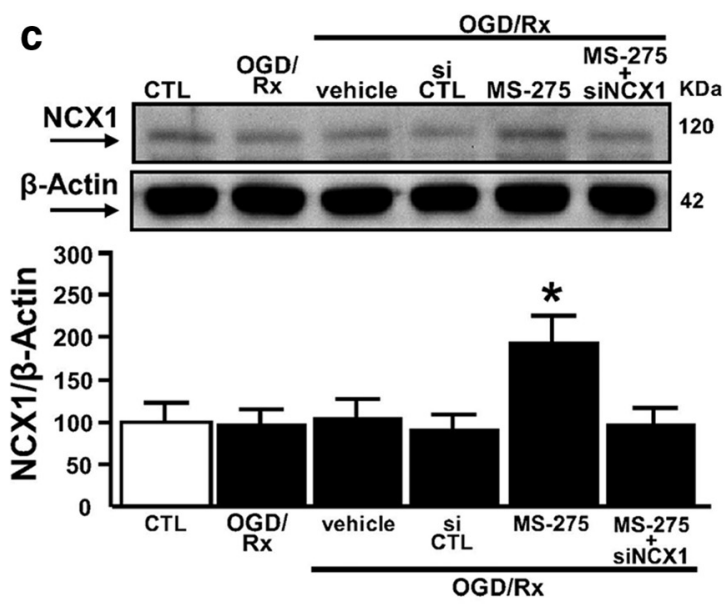

f
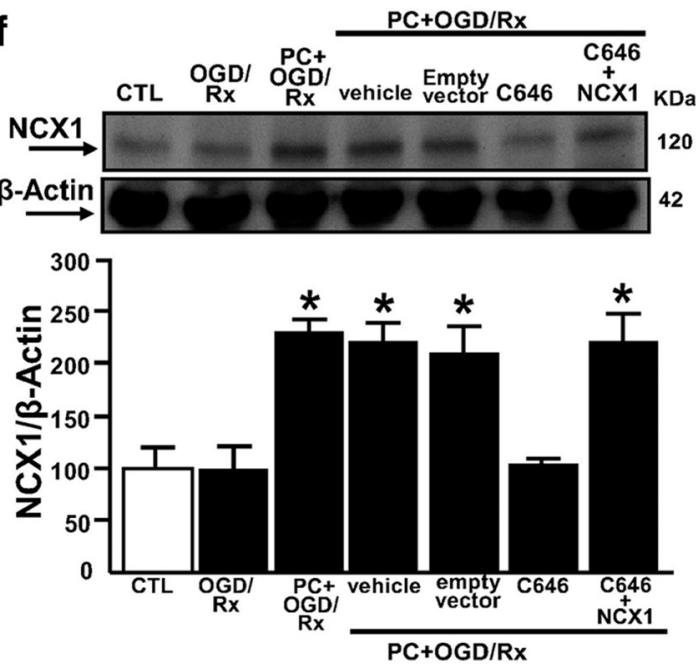

Figure 11. Effect of Class I HDAC inhibitor MS-275 and of HAT p300 inhibitor C646 on cell survival and NCX1 protein expression in cortical neurons exposed to 0GD/RX or to PC $+0 \mathrm{OGD} / \mathrm{RX}$, respectively. $\boldsymbol{a}$, Representative WB with quantification of $\mathrm{H3}$ acetyl in neurons subjected to $0 \mathrm{GD} / \mathrm{RX}$ alone or with MS-275. Each column represents the mean \pm SEM $(n=3)$. ${ }^{*} p<0.05$ versus

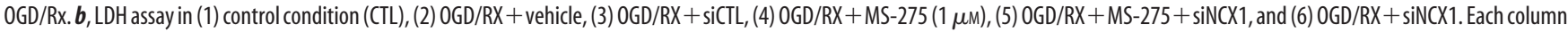
represents the mean \pm SEM $(n=5) .{ }^{*} p<0.05$ versus CTL. ${ }^{* *} p<0.05$ versus $0 \mathrm{GD} / \mathrm{Rx}+$ vehicle and $0 \mathrm{GD} / \mathrm{Rx}+$ siCTL. ${ }^{\#} p<0.05$ versus $0 \mathrm{GD} / \mathrm{Rx}+\mathrm{MS}-275 .{ }^{* * *} p<0.05$ versus all. c, NCX1 protein expression with quantification in (1) control condition (CTL), (2) OGD/RX, (3) OGD/RX+ vehicle, (4) OGD/RX + siCTL, (5) OGD/RX+ MS-275 (1 $\mu$ M), and (6) 0GD/RX + MS-275 + siNCX1. Each column represents the mean \pm SEM $(n=3) .{ }^{*} p<0.05$ versus all. $\boldsymbol{d}$, Representative WB with quantification of $\mathrm{H} 3$ acetyl in neurons subjected to $\mathrm{PC}+0 \mathrm{GD} / \mathrm{RX}$ alone or with $(646$. Each column represents the mean \pm SEM $(n=3) .{ }^{*} p<0.05$ versus $0 G D / R x . e, f$, LDH assay and NCX1 protein expression with quantification in (1) CTL, (2) PC, (3) $0 G D / R X$, (4) PC $+0 G D / R X,(5) P C+0 G D / R X+$ vehicle, (6) $\mathrm{PC}+0 \mathrm{GD} / \mathrm{RX}+$ empty vector, (7) PC+ OGD/RX + C646, and (8) PC +0GD/RX+ C646+NCX1. Each column represents the mean \pm SEM $(n=3$ for LDH assay and for WB). * $p<0.05$ versus $(T L$. ${ }^{* *} p<0.05$ versus all. ${ }^{\#} p<0.05$ versus $\mathrm{PC}+0 \mathrm{GD} / \mathrm{RX}$ alone or with vehicle and empty vector. ${ }^{\mathrm{p}} p<0.05$ versus $\mathrm{PC}+0 \mathrm{GD} / \mathrm{RX}+\mathrm{C} 646$.

sequence during tMCAO or PC+tMCAO, respectively. All these data suggest that the REST/Sp3/HDAC1/HDAC2 complex decreases NCX1 expression during brain ischemia, whereas the HIF-1/Sp1/p300 complex increases its expression during preconditioning. Notably, this regulation regards exclusively NCX1 and not NCX3, another NCX isoform involved in brain ischemia and ischemic brain preconditioning (Pignataro et al., 2012). Indeed, changes in NCX3 mRNA and protein expression were not associated with either the REST/Sp3/HDAC1/HDAC2 complex in tMCAO or the $\mathrm{PC}+\mathrm{tMCAO}$ complex in ischemic brain preconditioning. Furthermore, the rat Sp1C-E, repressor element 1 (RE-1) and hypoxia-responsive element-1 (HRE-1) sequences have $60 \%, 75 \%, 70 \%, 85 \%$, and $85 \%$ of similarity with human sequences, respectively. Fascinatingly, the positions of all the above mentioned sequences on ncxl human and rat promoters are conserved. This high percentage of homology between rat and human ncxl brain promoter sequences indicates the relevance of our results obtained in animal models of stroke to human brain ischemia. On the other hand, as REST (Calderone et al., 2003; Formisano et al., 2007; Ooi and Wood, 2007; Yeo et al., 2009), Sp1 and Sp3 (Bigger et al., 1997; Lee et al., 2006), and HIF-1 (Matrone et al., 2004) regulate also other genes, on the basis of our results, it cannot rule out that other proteins in coordination with NCX1 can participate in the physiopathology of stroke. About the mechanism(s) that trigger(s) the increase of REST and Sp3 by tMCAO and of HIF- 1 and Sp1 in PC + tMCAO, it has been reported that the increasing of REST expression in stroke has been associated with a decrease of casein kinase 1 (CK1) activation, which reduces REST phosphorylation blocking its proteasomal degradation (Kaneko et al., 2014), whereas the transcriptional repressor Sp3 is associated with CK2-phosphorylated histone deacetylase 2 (Sun et al., 2002), it could be suggested a role of CK1 to increase Sp3 and REST protein expression and their consequent binding on ncxl-Br promoter sequence. On the other hand, it has been found in $\mathrm{PC}+\mathrm{tMCAO}$ that $\mathrm{p}-\mathrm{AKT}$ inhibition prevented the upregulation of NCX1 (Pignataro et al., 2012) and that Sp1 and 
HIF- 1 are both targets of AKT (Jiang et al., 2001; Tan and Khachigian, 2009); therefore, it could be hypothesized that activation of this protein kinase during $\mathrm{PC}+\mathrm{tMCAO}$ determines an increase of Sp1 and HIF-1 binding on ncx1-Br promoter sequence. Furthermore, we investigated the role of HDAC1, HDAC2, and p300 in NCX1-induced neuroprotection in neurons subjected to either $\mathrm{OGD} / \mathrm{RX}$ or PC+OGD/RX. We observed that neuroprotection induced by the HDAC1 and HDAC2 inhibitor MS-275 was completely abolished during OGD/RX by silencing NCX1, a finding that further supports the tight relationship between HDAC1, HDAC2, and NCX1 in the pathophysiological processes leading to stroke. These results are in accordance with Noh et al. (2012), showing that HDAC1 and HDAC2 are recruited to the AMPA receptor subunit GluA2 promoter sequence and that injection of the pan-HDAC inhibitor thrichostatin A after an ischemic episode ameliorates neuronal injury. In addition, p300 inhibitor C646-induced cell death was completely reverted in $\mathrm{PC}+\mathrm{OGD} / \mathrm{RX}$ by NCX1 overexpression, thus suggesting a close relationship between the histone acetyltransferase p300 and NCX1 in ischemic preconditioning. In summary, we have shown that, under brain ischemia and brain ischemic preconditioning, NCX1 expression is epigenetically modulated, respectively, by two functional protein complexes: REST/Sp3/ HDAC1/HDAC2 and HIF-1/Sp1/p300. In particular, whereas the former downregulates NCX1 expression during brain ischemia, the latter upregulates it during preconditioning. Notably, the development of drugs that epigenetically regulate NCX1 by preventing its downregulation in stroke might be a new pharmacological avenue to ameliorate neuronal damage during brain ischemia.

\section{References}

Abel T, Zukin RS (2008) Epigenetic targets of HDAC inhibition in neurodegenerative and psychiatric disorders. Curr Opin Pharmacol 8:57-64. CrossRef Medline

Ammanamanchi S, Brattain MG (2001) Sp3 is a transcriptional repressor of transforming growth factor-beta receptors. J Biol Chem 276:3348-3352. CrossRef Medline

Ammanamanchi S, Freeman JW, Brattain MG (2003) Acetylated sp3 is a transcriptional activator. J Biol Chem 278:35775-35780. CrossRef Medline

Annunziato L, Pignataro G, Di Renzo GF (2004) Pharmacology of brain $\mathrm{Na}^{+} / \mathrm{Ca}^{2+}$ exchanger: from molecular biology to therapeutic perspectives. Pharmacol Rev 56:633-654. CrossRef Medline

Azahri NS, Di Bartolo BA, Khachigian LM, Kavurma MM (2012) Sp1, acetylated histone- 3 and $\mathrm{p} 300$ regulate TRAIL transcription: mechanisms of PDGF-BB-mediated VSMC proliferation and migration. J Cell Biochem 113:2597-2606. CrossRef Medline

Barone FC, White RF, Spera PA, Ellison J, Currie RW, Wang X, Feuerstein GZ (1998) Ischemic preconditioning and brain tolerance: temporal histological and functional outcomes, protein synthesis requirement, and interleukin-1 receptor antagonist and early gene expression. Stroke 29: 1937-1950; discussion 1950-1951. CrossRef Medline

Bigger CB, Melnikova IN, Gardner PD (1997) Sp1 and Sp3 regulate expression of the neuronal nicotinic acetylcholine receptor beta4 subunit gene. J Biol Chem 272:25976-25982. CrossRef Medline

Billon N, Carlisi D, Datto MB, van Grunsven LA, Watt A, Wang XF, Rudkin BB (1999) Cooperation of Sp1 and p300 in the induction of the CDK inhibitor p21WAF1/CIP1 during NGF-mediated neuronal differentiation. Oncogene 18:2872-2882. CrossRef Medline

Boscia F, Gala R, Pignataro G, de Bartolomeis A, Cicale M, AmbesiImpiombato A, Di Renzo G, Annunziato L (2006) Permanent focal brain ischemia induces isoform-dependent changes in the pattern of $\mathrm{Na}^{+} / \mathrm{Ca}^{2+}$ exchanger gene expression in the ischemic core, periinfarct area, and intact brain regions. J Cereb Blood Flow Metab 26:502-517. CrossRef Medline

Boscia F, D'Avanzo C, Pannaccione A, Secondo A, Casamassa A, Formisano L, Guida N, Sokolow S, Herchuelz A, Annunziato L (2012) Silencing or knocking out the $\mathrm{Na}(+) / \mathrm{Ca}(2+)$ exchanger-3 (NCX3) impairs oligodendrocyte differentiation. Cell Death Differ 19:562-572. CrossRef Medline Calderone A, Jover T, Noh KM, Tanaka H, Yokota H, Lin Y, Grooms SY, Regis R, Bennett MV, Zukin RS (2003) Ischemic insults derepress the gene silencer REST in neurons destined to die. J Neurosci 23:2112-2121. Medline

Carrasco-Serrano C, Campos-Caro A, Viniegra S, Ballesta JJ, Criado M (1998) GC- and E-box motifs as regulatory elements in the proximal promoter region of the neuronal nicotinic receptor alpha7 subunit gene. J Biol Chem 273:20021-20028. CrossRef Medline

Cassimere EK, Pyndiah S, Sakamuro D (2009) The c-MYC-interacting proapoptotic tumor suppressor BIN1 is a transcriptional target for E2F1 in response to DNA damage. Cell Death Differ 16:1641-1653. CrossRef Medline

Chuang DM, Leng Y, Marinova Z, Kim HJ, Chiu CT (2009) Multiple roles of HDAC inhibition in neurodegenerative conditions. Trends Neurosci 32:591-601. CrossRef Medline

Federman N, de la Fuente V, Zalcman G, Corbi N, Onori A, Passananti C, Romano A (2013) Nuclear factor $\kappa \mathrm{B}$-dependent histone acetylation is specifically involved in persistent forms of memory. J Neurosci 33:76037614. CrossRef Medline

Formisano L, Noh KM, Miyawaki T, Mashiko T, Bennett MV, Zukin RS (2007) Ischemic insults promote epigenetic reprogramming of mu opioid receptor expression in hippocampal neurons. Proc Natl Acad Sci U S A 104:4170-4175. CrossRef Medline

Formisano L, Saggese M, Secondo A, Sirabella R, Vito P, Valsecchi V, Molinaro P, Di Renzo G, Annunziato L (2008) The two isoforms of the $\mathrm{Na}^{+} /$ $\mathrm{Ca}^{2+}$ exchanger, NCX1 and NCX3, constitute novel additional targets for the prosurvival action of Akt/protein kinase B pathway. Mol Pharmacol 73:727-737. CrossRef Medline

Formisano L, Guida N, Valsecchi V, Pignataro G, Vinciguerra A, Pannaccione A, Secondo A, Boscia F, Molinaro P, Sisalli MJ, Sirabella R, Casamassa A, Canzoniero LM, Di Renzo G, Annunziato L (2013) NCX1 is a new rest target gene: role in cerebral ischemia. Neurobiol Dis 50:76-85. CrossRef Medline

Formisano L, Guida N, Laudati G, Boscia F, Esposito A, Secondo A, Di Renzo G, Canzoniero LM (2015a) Extracellular signal-related kinase 2/specificity protein 1 /specificity protein $3 /$ repressor element-1 silencing transcription factor pathway is involved in Aroclor 1254-induced toxicity in SH-SY5Y neuronal cells. J Neurosci Res 93:167-177. CrossRef Medline

Formisano L, Guida N, Laudati G, Mascolo L, Di Renzo G, Canzoniero LM (2015b) MS-275 inhibits aroclor 1254-induced SH-SY5Y neuronal cell toxicity by preventing the formation of the HDAC3/REST complex on the synapsin-1 promoter. J Pharmacol Exp Ther 352:236-243. CrossRef Medline

Galmozzi A, Mitro N, Ferrari A, Gers E, Gilardi F, Godio C, Cermenati G, Gualerzi A, Donetti E, Rotili D, Valente S, Guerrini U, Caruso D, Mai A, Saez E, De Fabiani E, Crestani M (2013) Inhibition of class I histone deacetylases unveils a mitochondrial signature and enhances oxidative metabolism in skeletal muscle and adipose tissue. Diabetes 62:732-742. CrossRef Medline

Guida N, Laudati G, Galgani M, Santopaolo M, Montuori P, Triassi M, Di Renzo G, Canzoniero LM, Formisano L (2014) Histone deacetylase 4 promotes ubiquitin-dependent proteasomal degradation of Sp3 in SH-SY5Y cells treated with di(2-ethylhexyl)phthalate (DEHP), determining neuronal death. Toxicol Appl Pharmacol 280:190-198. CrossRef Medline

Hagen G, Müller S, Beato M, Suske G (1992) Cloning by recognition site screening of two novel GT box binding proteins: a family of Sp1 related genes. Nucleic Acids Res 20:5519-5525. CrossRef Medline

Hwang CK, D’Souza UM, Eisch AJ, Yajima S, Lammers CH, Yang Y, Lee SH, Kim YM, Nestler EJ, Mouradian MM (2001) Dopamine receptor regulating factor, DRRF: a zinc finger transcription factor. Proc Natl Acad Sci U S A 98:7558-7563. CrossRef Medline

Iannotti FA, Barrese V, Formisano L, Miceli F, Taglialatela M (2013) Specification of skeletal muscle differentiation by repressor element-1 silencing transcription factor (REST)-regulated Kv7.4 potassium channels. Mol Biol Cell 24:274-284. CrossRef Medline

Ishimaru N, Tabuchi A, Hara D, Hayashi H, Sugimoto T, Yasuhara M, Shiota J, Tsuda M (2007) Regulation of neurotrophin-3 gene transcription by Sp3 and Sp4 in neurons. J Neurochem 100:520-531. CrossRef Medline

Isomura H, Stinski MF, Kudoh A, Daikoku T, Shirata N, Tsurumi T (2005) 
Two Sp1/Sp3 binding sites in the major immediate-early proximal enhancer of human cytomegalovirus have a significant role in viral replication. J Virol 79:9597-9607. CrossRef Medline

Iwamoto T, Inoue Y, Ito K, Sakaue T, Kita S, Katsuragi T (2004) The exchanger inhibitory peptide region-dependent inhibition of $\mathrm{Na}^{+} / \mathrm{Ca}^{2+}$ exchange by SN-6 [2-[4-(4-nitrobenzyloxy)benzyl]thiazolidine-4-carboxylic acid ethyl ester], a novel benzyloxyphenyl derivative. Mol Pharmacol 66:45-55. CrossRef Medline

Jiang BH, Jiang G, Zheng JZ, Lu Z, Hunter T, Vogt PK (2001) Phosphatidylinositol 3-kinase signaling controls levels of hypoxia-inducible factor 1. Cell Growth Differ 12:363-369. Medline

Jin HO, An S, Lee HC, Woo SH, Seo SK, Choe TB, Yoo DH, Lee SB, Um HD, Lee SJ, Park MJ, Kim JI, Hong SI, Rhee CH, Park IC (2007) Hypoxic condition- and high cell density-induced expression of Redd 1 is regulated by activation of hypoxia-inducible factor-1alpha and Sp1 through the phosphatidylinositol 3-kinase/Akt signaling pathway. Cell Signal 19: 1393-1403. CrossRef Medline

Kaneko N, Hwang JY, Gertner M, Pontarelli F, Zukin RS (2014) Casein kinase 1 suppresses activation of REST in insulted hippocampal neurons and halts ischemia-induced neuronal death. J Neurosci 34:6030-6039. CrossRef Medline

Ke Q, Costa M (2006) Hypoxia-inducible factor-1 (HIF-1). Mol Pharmacol 70:1469-1480. CrossRef Medline

Khalil MI, Hay J, Ruyechan WT (2008) Cellular transcription factors Sp1 and Sp3 suppress varicella-zoster virus origin-dependent DNA replication. J Virol 82:11723-11733. CrossRef Medline

Kim CS, Choi HS, Hwang CK, Song KY, Lee BK, Law PY, Wei LN, Loh HH (2006) Evidence of the neuron-restrictive silencer factor (NRSF) interaction with Sp3 and its synergic repression to the mu opioid receptor (MOR) gene. Nucleic Acids Res 34:6392-6403. CrossRef Medline

Ko JL, Liu HC, Minnerath SR, Loh HH (1998) Transcriptional regulation of mouse mu-opioid receptor gene. J Biol Chem 273:27678-27685. CrossRef Medline

Koh JY, Choi DW (1987) Quantitative determination of glutamate mediated cortical neuronal injury in cell culture by lactate dehydrogenase efflux assay. J Neurosci Methods 20:83-90. CrossRef Medline

Lanzillotta A, Pignataro G, Branca C, Cuomo O, Sarnico I, Benarese M, Annunziato L, Spano P, Pizzi M (2013) Targeted acetylation of NF-kap$\mathrm{paB} /$ RelA and histones by epigenetic drugs reduces post-ischemic brain injury in mice with an extended therapeutic window. Neurobiol Dis 49: 177-189. CrossRef Medline

Law AY, Yeung BH, Ching LY, Wong CK (2011) Sp1 is a transcription repressor to stanniocalcin-1 expression in TSA-treated human colon cancer cells, HT29. J Cell Biochem 112:2089-2096. CrossRef Medline

Lee J, Kosaras B, Aleyasin H, Han JA, Park DS, Ratan RR, Kowall NW, Ferrante RJ, Lee SW, Ryu H (2006) Role of cyclooxygenase-2 induction by transcription factor Sp1 and Sp3 in neuronal oxidative and DNA damage response. FASEB J 20:2375-2377. CrossRef Medline

Lerner LE, Gribanova YE, Whitaker L, Knox BE, Farber DB (2002) The rod cGMP-phosphodiesterase beta-subunit promoter is a specific target for Sp4 and is not activated by other Sp proteins or CRX. J Biol Chem 277: 25877-25883. CrossRef Medline

Lerner LE, Peng GH, Gribanova YE, Chen S, Farber DB (2005) Sp4 is expressed in retinal neurons, activates transcription of photoreceptorspecific genes, and synergizes with Crx. J Biol Chem 280:20642-20650. CrossRef Medline

Matrone C, Pignataro G, Molinaro P, Irace C, Scorziello A, Di Renzo GF, Annunziato L (2004) HIF-lalpha reveals a binding activity to the promoter of iNOS gene after permanent middle cerebral artery occlusion. J Neurochem 90:368-378. CrossRef Medline

Min SW, Cho SH, Zhou Y, Schroeder S, Haroutunian V, Seeley WW, Huang EJ, Shen Y, Masliah E, Mukherjee C, Meyers D, Cole PA, Ott M, Gan L (2010) Acetylation of tau inhibits its degradation and contributes to tauopathy. Neuron 67:953-966. CrossRef Medline

Mora-López F, Pedreño-Horrillo N, Delgado-Pérez L, Brieva JA, CamposCaro A (2008) Transcription of PRDM1, the master regulator for plasma cell differentiation, depends on an SP1/SP3/EGR-1 GC-box. Eur J Immunol 38:2316-2324. CrossRef Medline

Nguyen-Huynh AT, Schaffer PA (1998) Cellular transcription factors enhance herpes simplex virus type 1 oriS-dependent DNA replication. J Virol 72:3635-3645. Medline

Noh KM, Hwang JY, Follenzi A, Athanasiadou R, Miyawaki T, Greally JM, Bennett MV, Zukin RS (2012) Repressor element-1 silencing transcrip- tion factor (REST)-dependent epigenetic remodeling is critical to ischemia-induced neuronal death. Proc Natl Acad Sci U S A 109:E962E971. CrossRef Medline

Ooi L, Wood IC (2007) Chromatin crosstalk in development and disease: lessons from REST. Nat Rev Genet 8:544-554. CrossRef Medline

Pawlus MR, Hu CJ (2013) Enhanceosomes as integrators of hypoxia inducible factor (HIF) and other transcription factors in the hypoxic transcriptional response. Cell Signal 25:1895-1903. CrossRef Medline

Philipsen S, Suske G (1999) A tale of three fingers: the family of mammalian Sp/XKLF transcription factors. Nucleic Acids Res 27:2991-3000. CrossRef Medline

Pignataro G, Gala R, Cuomo O, Tortiglione A, Giaccio L, Castaldo P, Sirabella R, Matrone C, Canitano A, Amoroso S, Di Renzo G, Annunziato L (2004) Two sodium/calcium exchanger gene products, NCX1 and NCX3, play a major role in the development of permanent focal cerebral ischemia. Stroke 35:2566-2570. CrossRef Medline

Pignataro G, Esposito E, Cuomo O, Sirabella R, Boscia F, Guida N, Di Renzo G, Annunziato L (2011) The NCX3 isoform of the $\mathrm{Na}^{+} / \mathrm{Ca}^{2+}$ exchanger contributes to neuroprotection elicited by ischemic postconditioning. J Cereb Blood Flow Metab 31:362-370. CrossRef Medline

Pignataro G, Boscia F, Esposito E, Sirabella R, Cuomo O, Vinciguerra A, Di Renzo G, Annunziato L (2012) NCX1 and NCX3: two new effectors of delayed preconditioning in brain ischemia. Neurobiol Dis 45:616-623. CrossRef Medline

Pinacho R, Villalmanzo N, Lalonde J, Haro JM, Meana JJ, Gill G, Ramos B (2011) The transcription factor SP4 is reduced in postmortem cerebellum of bipolar disorder subjects: control by depolarization and lithium. Bipolar Disord 13:474-485. CrossRef Medline

Plaisance V, Niederhauser G, Azzouz F, Lenain V, Haefliger JA, Waeber G, Abderrahmani A (2005) The repressor element silencing transcription factor (REST)-mediated transcriptional repression requires the inhibition of Sp1. J Biol Chem 280:401-407. CrossRef Medline

Ramos B, Gaudillière B, Bonni A, Gill G (2007) Transcription factor Sp4 regulates dendritic patterning during cerebellar maturation. Proc Natl Acad Sci U S A 104:9882-9887. CrossRef Medline

Ramos B, Valín A, Sun X, Gill G (2009) Sp4-dependent repression of neurotrophin-3 limits dendritic branching. Mol Cell Neurosci 42:152159. CrossRef Medline

Ravache M, Weber C, Mérienne K, Trottier Y (2010) Transcriptional activation of REST by Sp1 in Huntington's disease models. PLoS One 5:e14311. CrossRef Medline

Renthal W, Maze I, Krishnan V, Covington HE 3rd, Xiao G, Kumar A, Russo SJ, Graham A, Tsankova N, Kippin TE, Kerstetter KA, Neve RL, Haggarty SJ, McKinsey TA, Bassel-Duby R, Olson EN, Nestler EJ (2007) Histone deacetylase 5 epigenetically controls behavioral adaptations to chronic emotional stimuli. Neuron 56:517-529. CrossRef Medline

Rodenas-Ruano A, Chávez AE, Cossio MJ, Castillo PE, Zukin RS (2012) REST-dependent epigenetic remodeling promotes the developmental switch in synaptic NMDA receptors. Nat Neurosci 15:1382-1390. CrossRef Medline

Ryu H, Lee J, Zaman K, Kubilis J, Ferrante RJ, Ross BD, Neve R, Ratan RR (2003) Sp1 and Sp3 are oxidative stress-inducible, antideath transcription factors in cortical neurons. J Neurosci 23:3597-3606. Medline

Schweizer S, Meisel A, Märschenz S (2013) Epigenetic mechanisms in cerebral ischemia. J Cereb Blood Flow Metab 33:1335-1346. CrossRef Medline

Simonini MV, Camargo LM, Dong E, Maloku E, Veldic M, Costa E, Guidotti A (2006) The benzamide MS-275 is a potent, long-lasting brain regionselective inhibitor of histone deacetylases. Proc Natl Acad Sci U S A 103: 1587-1592. CrossRef Medline

Sirabella R, Secondo A, Pannaccione A, Scorziello A, Valsecchi V, Adornetto A, Bilo L, Di Renzo G, Annunziato L (2009) Anoxia-induced NFkappaB-dependent upregulation of NCX1 contributes to $\mathrm{Ca}^{2+}$ refilling into endoplasmic reticulum in cortical neurons. Stroke 40:922-929. CrossRef Medline

Sirabella R, Secondo A, Pannaccione A, Molinaro P, Formisano L, Guida N, Di Renzo G, Annunziato L, Cataldi M (2012) ERK1/2, p38, and JNK regulate the expression and the activity of the three isoforms of the $\mathrm{Na}(+)$ $/ \mathrm{Ca}(2+)$ exchanger, NCX1, NCX2, and NCX3, in neuronal PC12 cells. J Neurochem 122:911-922. CrossRef Medline

Sisalli MJ, Secondo A, Esposito A, Valsecchi V, Savoia C, Di Renzo GF, An- 
nunziato L, Scorziello A (2014) Endoplasmic reticulum refilling and mitochondrial calcium extrusion promoted in neurons by NCX1 and NCX3 in ischemic preconditioning are determinant for neuroprotection. Cell Death Differ 21:1142-1149. CrossRef Medline

Stains JP, Lecanda F, Screen J, Towler DA, Civitelli R (2003) Gap junctional communication modulates gene transcription by altering the recruitment of Sp1 and Sp3 to connexin-response elements in osteoblast promoters. J Biol Chem 278:24377-24387. CrossRef Medline

Sun JM, Chen HY, Moniwa M, Litchfield DW, Seto E, Davie JR (2002) The transcriptional repressor Sp3 is associated with CK2-phosphorylated histone deacetylase 2. J Biol Chem 277:35783-35786. CrossRef Medline

Suske G (1999) The Sp-family of transcription factors. Gene 238:291-300. CrossRef Medline
Tan NY, Khachigian LM (2009) Sp1 phosphorylation and its regulation of gene transcription. Mol Cell Biol 29:2483-2488. CrossRef Medline

Valsecchi V, Pignataro G, Del Prete A, Sirabella R, Matrone C, Boscia F, Scorziello A, Sisalli MJ, Esposito E, Zambrano N, Di Renzo G, Annunziato L (2011) NCX1 is a novel target gene for hypoxia-inducible factor-1 in ischemic brain preconditioning. Stroke 42:754-763. CrossRef Medline

Won J, Yim J, Kim TK (2002) Sp1 and Sp3 recruit histone deacetylase to repress transcription of human telomerase reverse transcriptase (hTERT) promoter in normal human somatic cells. J Biol Chem 277:38230-38238. CrossRef Medline

Yeo M, Berglund K, Augustine G, Liedtke W (2009) Novel repression of Kcc2 transcription by REST-RE-1 controls developmental switch in neuronal chloride. J Neurosci 29:14652-14662. CrossRef Medline 